\title{
From Good to Great
}

Exemplary Teachers Share Perspectives on Increasing Teacher Effectiveness Across the Career Continuum

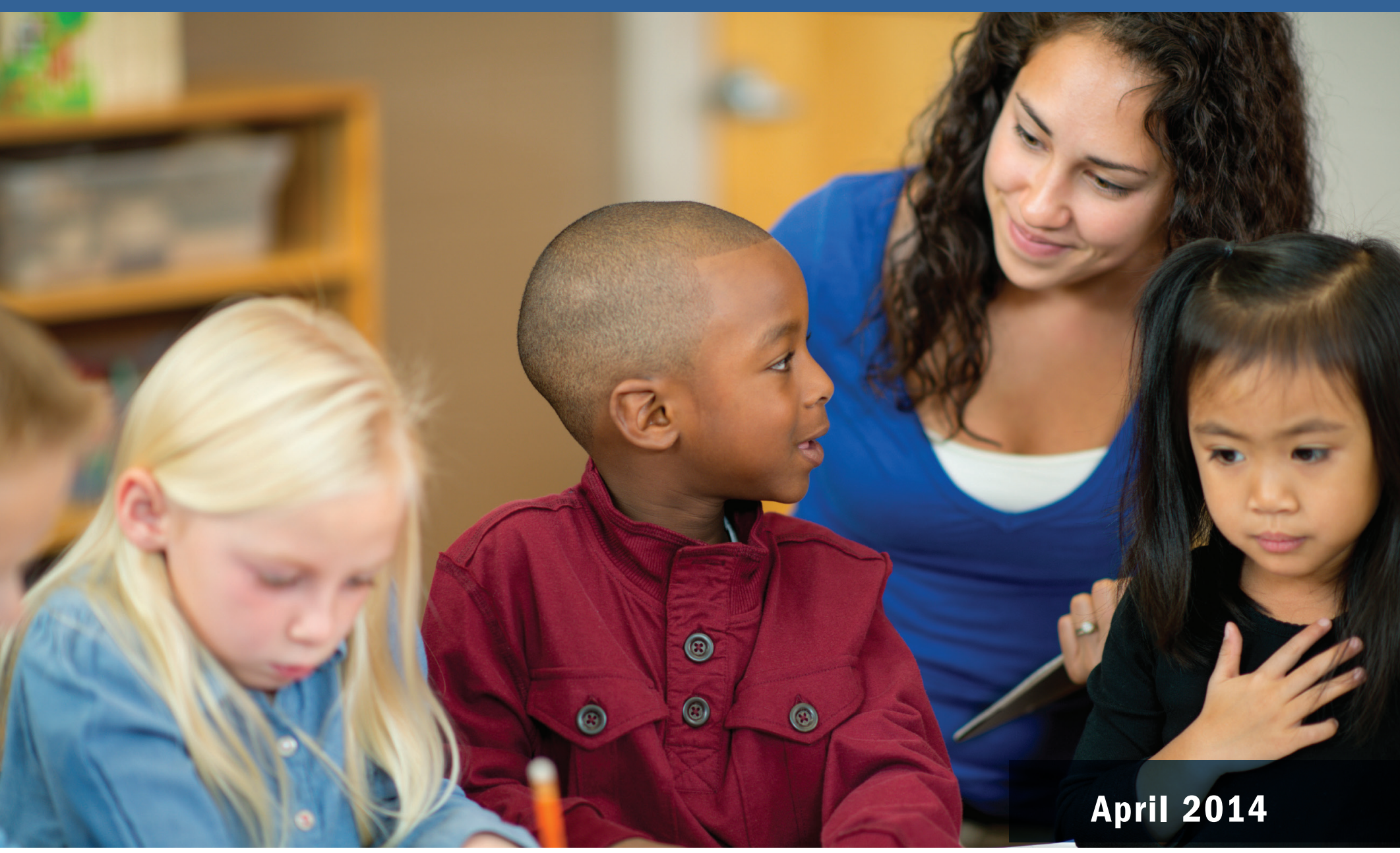

GREAT TEACHERS \& LEADERS

CAEP $=$ 


\section{Acknowledgments}

The authors wish to thank the following individuals from the partner organizations, who played key roles in shaping this project: Angela Minnici, Ph.D., Pia Peltola, Ph.D., Jane Coggshall, Ph.D., Robert Stonehill, Ph.D., Gretchen Weber, Jenni Fetters, Jan Gahala, Laura King, and Sabrina Laine, Ph.D., from American Institutes for Research; Philip Bigler, 1998 National Teacher of the Year, from James Madison University; Jon Quam, from the Council of Chief State School Officers; Katie Moyer and Nancy Waymack from the National Council on Teacher Quality; Bill Raabe, Jennifer Locke, and Julia Lara, Ph.D., from the National Education Association; Jane West, Ph.D., Saroja Barnes, Ph.D., and Jessica Milton, from the American Association of Colleges of Teacher Education; Jennifer Carinci and Mishaela Duran, from the Council for the Accreditation of Educator Preparation; and Lucy Steiner and Grace Han, from Public Impact. The report would not have been possible without the insight and wisdom that each of these individuals brought to the table.

The authors also are very grateful for the thoughtful reviews of this report conducted by David Bosso, 2012 Connecticut State Teacher of the Year, from Berlin (Connecticut) Public Schools; Jennifer YorkBarr, Ph.D., from the University of Minnesota; Kelly Henson, from the Georgia Professional Standards Commission; and Kelly Kovacic, 2010 California State Teacher of the Year and student at Harvard Graduate School of Education. 


\title{
From Good to Great
}

\section{Exemplary Teachers Share Perspectives on Increasing Teacher Effectiveness Across the Career Continuum}

\author{
APRIL 2014 \\ Ellen Behrstock-Sherratt, Ph.D. \\ American Institutes for Research \\ Katherine Bassett \\ National Network of State Teachers of the Year \\ 2000 New Jersey State Teacher of the Year \\ Derek Olson \\ Stillwater Area (Minnesota) Public Schools \\ 2009 Minnesota State Teacher of the Year \\ Catherine Jacques \\ American Institutes for Research
}





\section{Contents}

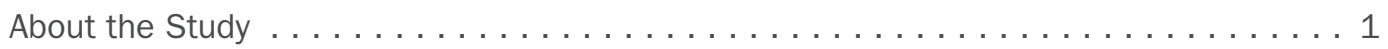

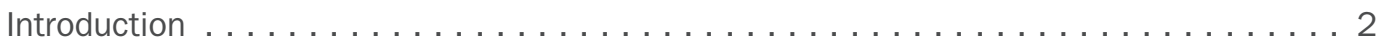

About This Survey: A Teacher-Led Design $\ldots \ldots \ldots \ldots \ldots \ldots \ldots \ldots \ldots \ldots$

Stages of the Teacher Career Continuum Represented in the Survey . . . . . . . . . .4

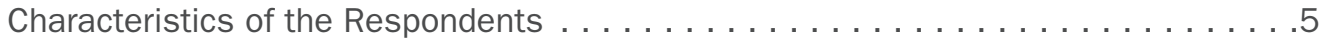

Why Survey National and State Teachers of the Year? $\ldots \ldots \ldots \ldots \ldots \ldots \ldots$

The Survey Instrument. . . . . . . . . . . . . . . . . . . . . . . .6

Findings Related to Each Stage of the Teacher Career Continuum . . . . . . . . . . 7

Preservice Stage . . . . . . . . . . . . . . . . . . . .

Novice Stage. . . . . . . . . . . . . . . . . . . . . . . . . . . . . . . 12

Career Stage . . . . . . . . . . . . . . . . . . . . . . . . . . . . . . . . . 15

Teacher Leader Stage . . . . . . . . . . . . . . . . . . . . . . . . . 20

Considerations . . . . . . . . . . . . . . . . . . . . 23

Next Steps . . . . . . . . . . . . . . . . . . . . . . . . . . . . . 25

References.............................. 26

Appendix. Methodology for the Survey $\ldots \ldots \ldots \ldots \ldots \ldots \ldots \ldots \ldots \ldots \ldots \ldots$ 



\section{About the Study}

This report is the result of a yearlong collaboration among seven leading organizations working to advance teaching and elevate the profession. Proposed by the National Network of State Teachers of the Year (NNSTOY) and led by the Center on Great Teachers and Leaders (GTL Center) at American Institutes for Research, the study involves the following partner organizations, which collaborated extensively on this study, contributing to the development of the survey questions, data analysis, and drafting of the report:

- American Association of Colleges of Teacher Education

- Council for the Accreditation of Educator Preparation

- Council of Chief State School Officers

- GTL Center

- National Council on Teacher Quality

- National Education Association

- NNSTOY

This report represents merely the beginning of our work together. Plans for the future include:

- Expanding the survey used in this report to other effective teachers beyond the State and National Teachers of the Year (such as other award-winning teachers, teachers certified by the National Board for Professional Teaching Standards, or teachers who received high ratings on their evaluations)

- Unpacking the survey data through interviews and focus groups to gain a deeper understanding of why these effective teachers responded as they did

- Conducting a similar study focused exclusively on new teachers-particularly new teachers in settings that have implemented innovative reforms-to gain insights about the current status of reform efforts to improve teacher effectiveness

\section{Study Materials}

In addition to this report, the following study materials are available online:

- Executive summary

- Survey instrument

- Survey results

- Discussion starter tool

All these materials are available for download on the GTL Center's From Good to Great webpage. Please visit the webpage at http:// www.gtlcenter.org/products-resources/study-teacher-perspectivesfactors-influencing-effectiveness. 


\section{Introduction}

For well over a decade, teachers have been recognized as the single most important school-level factor influencing student achievement (Darling-Hammond, 2000; McCaffrey, Lockwood, Koretz, \& Hamilton, 2003; Rivkin, Hanushek, \& Kain, 2000; Rowan, Correnti \& Miller, 2002; Wright, Horn, \& Sanders, 1997). Tremendous public resources have been invested across the country in new systems to both assess and address teacher effectiveness. Yet the lion's share of existing research seeking to understand the factors that make teachers effective focuses on quantifiable-yet more surface-level—inputs, such as years on the job, grade point averages, certifications, and degrees. This research leaves many important policy questions unanswered-particularly questions about the specific types of professional experiences and supports necessary to maximize teacher effectiveness.

This report helps to fill these gaps through a first-of-its-kind exploratory survey of National and State Teachers of the Year. These teachers are chosen by their states as among the best, and one teacher each year is selected as among the best in the nation (see "Who Are the National and State Teachers of the Year?" on page 3). In this report, we offer insights on the professional experiences and supports that these teachers believe most contributed to their growth and eventual excellence as a teacher.

Reflecting back on their careers, from preparation through mastery and even into retirement, the National and State Teachers of the Year surveyed in this study provide education leaders and policymakers with needed information about the formative experiences of great teachers. The findings both surprise us and confirm much of what we knew about how teachers evolve from good to great.

The main body of the report takes readers through the four stages that this study used to define the teacher career continuum: Preservice, Novice, Career, and Teacher Leader stages. For each stage, it describes the professional experiences and supports that the National and State Teachers of the Year viewed as increasing teacher effectiveness as they progressed through the stages of their career. The report concludes with considerations for policymakers at the school, district, and state levels as well as for teacher preparation programs.

The question of which professional experiences and supports teachers view as the most critical for improving teacher effectiveness is widely relevant to researchers, policymakers, and practitioners alike. For the research audience, this report provides a brief description of the methodological approach used in this study, with a more technical description in the Appendix. The survey instrument and survey results are available online (http:// www.gtlcenter.org/products-resources/study-teacher-perspectives-factors-influencingeffectiveness). For the policy and practitioner audience, a companion Discussion Starter Tool for sparking discussions on how to use the data in this report to improve teacher effectiveness supports also is available (http://www.gtlcenter.org/products-resources/ study-teacher-perspectives-factors-influencing-effectiveness). 


\section{Who Are the National and State Teachers of the Year?}

The National Network of State Teachers of the Year (NNSTOY) is the organization that represents educators selected by their states (including the District of Columbia, the Department of Defense Education Activity, and U.S. overseas territories) as the official State Teacher of the Year. The selection process varies by state, but each state's process aims to rigorously validate the State Teacher of the Year's abilities in the classroom, in communicating with broad audiences, and in representing the teaching profession.

These teachers serve as representatives to the Council of Chief State School Officers (CCSSO) National Teacher of the Year Program during their Year of Recognition and are eligible to be selected as the National Teacher of the Year. The selected State Teachers of the Year spend time training with CCSSO in the areas of policy and advocacy. NNSTOY is the organization that serves as their professional home after the Year of Recognition, in what State Teachers of the Year call their "Years of Service," giving back to the profession and sharing what they have learned.

For more information about State Teachers of the Year, please see http://www.nnstoy.org/; for more information about National Teachers of the Year, please see http://www.ccsso.org/ntoy.html.

\section{About This Survey: A Teacher-Led Design}

A growing body of literature highlights the importance and desire of practicing teachers to participate in the design, execution, and reporting of educational research and to contribute to the policy dialogue (Behrstock-Sherratt, Rizzolo, Laine, \& Friedman, 2013; Bosso, 2014; Coggins, Peske, \& McGovern, 2013; Drill, Miller, \& Behrstock-Sherratt, 2013). This study responds to that call.

The survey was a true collaboration with our partner organizations, which participated in all aspects of the study — from design to dissemination. It also was fundamentally informed by teachers. The survey content was shaped by National and State Teachers of the Year focus groups, which convened at the initial and final stages of survey design, and State Teacher of the Year teacher researchers coauthored it. This study contributes to the current body of teacher effectiveness research both by asking effective teachers about their own views on the factors influencing teacher effectiveness and by heavily incorporating teacher voice and leadership in all aspects of the study.

The overriding research question that the survey set out to address was What experiences and supports led these exemplary teachers to become so effective? The term "effective" was loosely defined; all respondents had been recognized publicly for demonstrating exemplary teaching practices, but the survey also allowed these award-winning teachers 
to interpret the term "effective" in their own personal way as they responded to questions about the experiences and supports that led them to be so. The survey captured the perceptions of the respondents, based on their personal experience, on topics such as:

- Aspects of their teacher preparation programs that most contributed to their instructional excellence

- Characteristics of their mentoring and induction experiences that strengthened their practice as a novice teacher

- Ongoing professional learning activities that were particularly effective

- Leadership training or opportunities to develop other teachers' effectivenesswhich, in turn, improved their own practice

\section{Stages of the Teacher Career Continuum Represented in the Survey}

Starting by using the Dreyfus and Dreyfus (1986) model of the career continuum as a basis, the partner organizations collectively drew from prior research and field work to generate a comprehensive list of survey items that span the stages of the teacher career continuum, as depicted in Figure 1.

- Preservice Stage: The period of teachers' careers when they were preparing to teach

- Novice Stage: ${ }^{1}$ Years 1-5 as teachers of record

- Career Stage: Year 6 and on, having reached a certain level of mastery but before taking on significant leadership roles

- Teacher Leader Stage: The point after which teachers became a State Teacher of the Year and/or assumed other teacher leadership responsibilities

Figure 1. The Continuum of Professional Practice Development

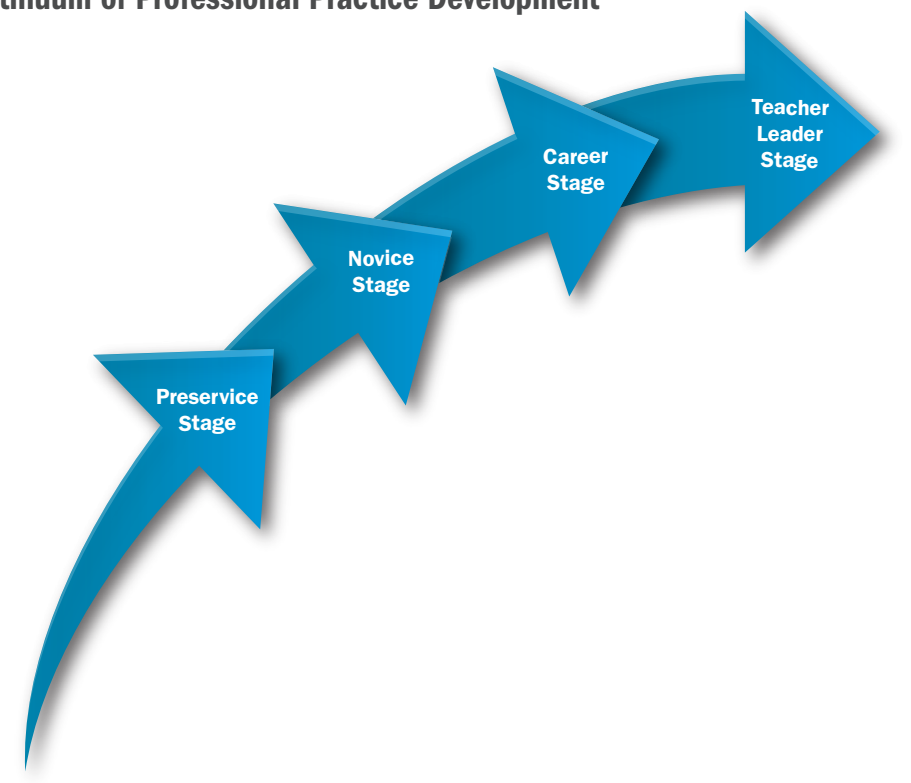

1 In the survey instrument, this stage was called Novice and Advanced Beginner Stage. Current use of Novice Stage reflects Novice and Advanced Beginner Stage responses. 


\section{Characteristics of the Respondents}

Of the 755 National and State Teachers of the Year who received an invitation to participate in the study, 311 (41 percent) completed the survey. The survey respondents are broadly representative of the full population of National and State Teachers of the Year and U.S. teachers in general. Specifically, as shown in Table A2 in the Appendix, respondents represented the full spectrum of subject areas taught, types of school locations (urban, rural, suburban), school poverty level, and grade levels. Ninety-nine percent of respondents teach or taught in traditional public schools at some point during their career.

However, an important caveat is that although 50 percent of survey respondents currently were teaching in a PK-12 classroom (as a teacher or in a specialist role), the remaining 50 percent were in school or district administration, universities, or nonprofit organizations. In addition, 15 percent of the respondents already had retired. Likewise, 58 percent had worked in the classroom for 20 years or more, as shown in Figure 2.

More information about the methodological approach and the characteristics of the 311 respondents is detailed in the Appendix.

Figure 2. Respondents' Total Years of PK-12 Teaching Experience

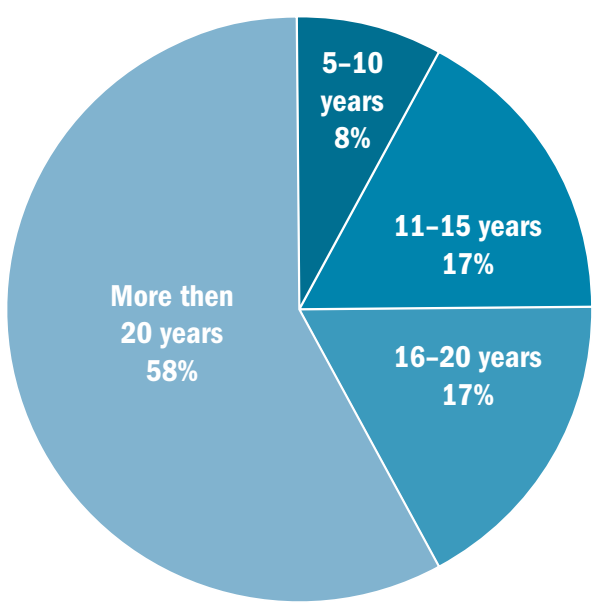

\section{Why Survey National and State Teachers of the Year?}

Because the population included all National and State Teachers of the Year from the mid-1970s through 2013, this survey represents these teachers' reflections as they look back on their careers at the professional experiences and supports that helped them teach well. The time frame in which the teachers had these experiences and supports ranges from very recent to many years past. Thus, on one hand, this survey does not necessarily reflect the typical experiences of many current teacher leaders nor does it necessarily capture the current status of teacher preparation or novice teacher supports. On the other hand, surveying National and State Teachers of the Year who have experienced a large range 
of professional supports over many years and have continually engaged in reflection on the value of each support provides a unique breadth of perspective to contribute to the field. A useful follow-up study might be a survey of newly minted effective teachers on the aspects of their preparation programs and novice teacher supports that helped them succeed in their early days in the classroom. Nevertheless, the findings in this report provide insights from a thoughtful group of practitioners who possess great breadth of experience; these findings also offer a useful launching point and basis of comparison for further research on views of inexperienced yet effective teachers regarding the usefulness of supports received thus far.

\section{The Survey Instrument}

To generate the survey items, the partner organizations collectively developed a list of 163 professional experiences and supports that might contribute to a teacher's success. Then they asked National and State Teachers of the Year the following series of questions at each stage along the career continuum:

\section{- Question 1: Did you have the professional learning experience or support as a} means of strengthening your effectiveness?

Although the primary purpose of our survey was to determine which experiences and supports National and State Teachers of the Year believe led them to be effective, we first had to determine which experiences and supports they actually had. The survey items established the common experiences and supports for these effective teachers as well as the experiences and supports that might be seen as critical to a teacher's effectiveness but perhaps were absent in these excellent teachers' careers.

- Question 2: For the professional learning experiences and supports that you received, how important (on a 1-5 scale) were they for increasing your effectiveness as a teacher?

This Likert scale allowed us to identify the percentage of survey respondents who viewed each experience and support as "important" or "very important." To further clarify which of the "very important" experiences and supports were the most important, we followed up with Question 3.

- Question 3: Of the experiences and supports that you ranked as "very Important," which three, in order, do you rank as the most important for improving your effectiveness as a teacher?

This final ranking of the first, second, and third most important experiences and supports at each level of the continuum was a critical component of this survey and the focus of the sections that follow.

The survey items and survey responses are available online (http://www.gtlcenter.org/ products-resources/study-teacher-perspectives-factors-influencing-effectiveness). 


\title{
Findings Related to Each Stage of the Teacher Career Continuum
}

\author{
Preservice Stage
}

"Too many future teachers graduate from preparation programs unprepared for success in the classroom," declared U.S. Secretary of Education Arne Duncan in 2011 (U.S. Department of Education, 2011). Research likewise suggests that teacher preparation programs have room to improve, although by no means do all teachers feel that their preservice training left them unprepared when they entered the classroom. For example, the 2007-08 national Schools and Staffing Survey found that the vast majority of teachers across the country felt either "somewhat prepared" or "well prepared" to select and adapt curriculum and instructional materials, to assess students, and to handle a range of classroom management or discipline situations when they entered the classroom; however, only 1 in 5 teachers felt "very well prepared" for these responsibilities (as reported in Coggshall, Bivona, \& Reschly, 2012).

We surveyed the National and State Teachers of the Year on specific aspects of their preparation experience to help pinpoint high-impact practices of their preparation program that contributed to them becoming effective teachers. Because so many preservice experiences were seen as valuable, we asked them to rank the most important of those they had experienced and found to be "very important" (see Figure 3 on page 8).

It is worth pointing out that 58 percent of survey respondents completed their teacher preparation more than 20 years ago. Therefore, the findings illustrated in Figure 3 should be read not as a reflection of the current state of today's teacher preparation programs but rather as the reflections of effective teachers as they more broadly recollected the early experiences that helped them along their journey to becoming an excellent teacher. Relatedly, it is important to point out that the findings primarily pertain to bachelor's degree programs, which is how two thirds of survey respondents were certified. (For the remaining respondents, 13 percent were certified through a master's program, 10 percent completed a postbaccalaureate degree, 6 percent completed an alternative certification program, and 6 percent were certified through other means.) Further research and use of our companion Discussion Starter Tool (available online at http://www.gtlcenter.org/productsresources/study-teacher-perspectives-factors-influencing-effectiveness) can provide insights into the valuable aspects of preservice training in specific present-day contexts. 
Top On the List: The Final Clinical Practicum. Trumping all other supports at the Preservice Stage in its importance to developing teacher effectiveness is access to a high-quality clinical practicum (often referred to as student teaching or an internship). We found that fully 88 percent of National and State Teacher of the Year respondents had access to a final clinical practicum that they found to be high quality, and nearly three quarters of this group ranked the experience as among the three most important aspects of their preservice experience (see Figure 3). ${ }^{2}$

This result is perhaps not surprising, given prior studies that indicate the importance of the teacher-preparation clinical experience in promoting teacher effectiveness (Boyd, Grossman, Lankford, Loeb, \& Wyckoff, 2009; Hart, 2008; Levine, 2006; Markow \& Martin, 2005; National Research Council, 2010).

Figure 3. Percentage of National and State Teachers of the Year Who Ranked Each Preservice Support Among the "Top Three" for Developing Their Effectiveness as a Teacher

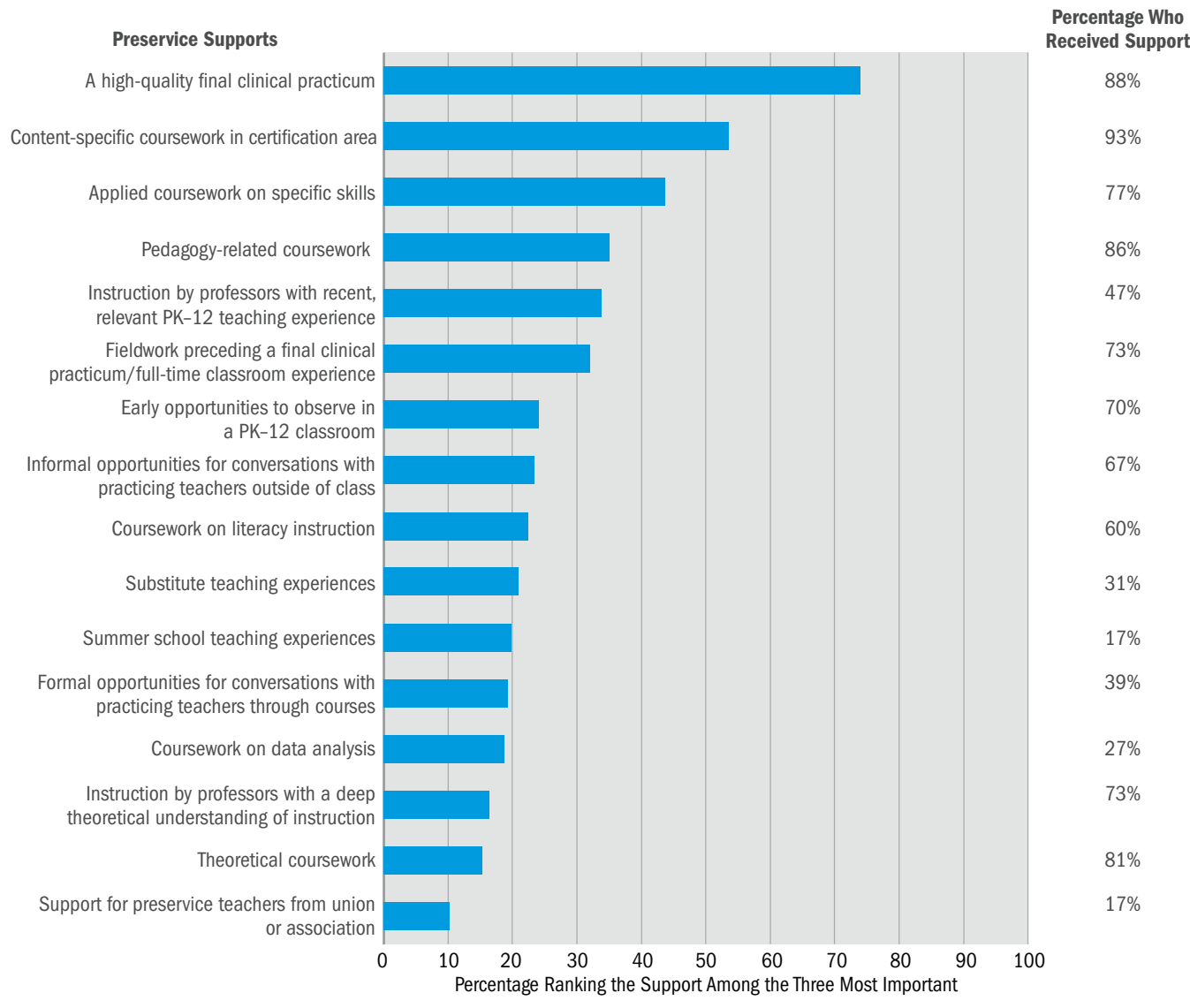

2 A caveat in interpreting the "top three" rankings here and throughout the report is that the characteristics and quality of many experiences and supports are not specified; most of these experiences and supports can be delivered in multiple ways, with varying degrees of quality. For example, the Figure 3 finding that preservice theoretical coursework was ranked low (with only 15 percent of respondents ranking it among their "top 3" most important supports at this stage) could mean either (a) that this support inherently is less helpful than the others; or (b) that the type of theoretical coursework was less helpful than it potentially can be, and, if preparation programs improve their delivery of theoretical coursework, this support may well be more highly ranked. Our survey is not able to disentangle these two possibilities. 
Which Coursework Counts? As shown in Figure 3, we asked National and State Teachers of the Year about the value of a range of coursework in raising their effectiveness at the Preservice Stage: theoretical coursework, content-specific coursework, pedagogical coursework, applied coursework on specific skills, literacy instruction coursework, and data analysis coursework. In line with prior studies indicating that a teacher's content-area expertise significantly affects student achievement (Darling-Hammond, 2000; Hill, Rowan, \& Ball, 2005), we found that 78 percent of the surveyed National and State Teachers of the Year reported that preservice content coursework was "very important" to their own effectiveness. And, as shown in Figure 3, just over half viewed content-specific coursework as among the top three most important preservice experiences for developing their effectiveness as teachers.

\section{Trends to Follow: Which Types of Preparation Coursework Are Teachers Taking?}

Bearing in mind that no respondents had fewer than five years of experience (and only 24 respondents, or 8 percent, had 5-10 years of experience), some noteworthy trends emerged that are worth exploring in future studies that include larger samples of recently prepared effective teachers:

- Thirty-six percent of survey respondents with 5-10 years of experience had data analysis coursework at the Preservice Stage, compared to only about a quarter of teachers with $11+$ years of experience.

- Seventy-four percent of survey respondents with 5-10 years of experience had literacy coursework at the Preservice Stage, compared to just under 60 percent of teachers with $11+$ years of experience.

Coursework for teacher preparation programs has sometimes been criticized as too theoretical and lacking in relevance (Levine, 2006), a finding that was reiterated here. Only 15 percent of survey respondents considered theoretical coursework to be a top-ranking contributor to their effectiveness, as shown in Figure 3. To help teacher preparation programs make informed decisions on how to improve their theoretical coursework, we presented the National and State Teachers of the Year with a list of more specific theoretical courses and found that between two thirds and three quarters of respondents did in fact suggest that the following three courses "significantly improved their effectiveness":

- Managing Student Behavior (74 percent)

- Human Development (71 percent)

- Learning and the Brain (64 percent) 
Does It Matter Who Teaches Preservice Courses? Though less important to our respondents than other aspects of preparation, also worth noting was the importance of having professors with recent $\mathrm{K}-12$ experience. One national survey found that almost

One third of the nearly half of National and State Teacher of the Year respondents who had access to professors with recent PK-12 teaching experience cited this experience as one of the top three most important contributors to their effective development. half (42 percent) of those who teach preservice candidates have either never been a classroom teacher or have not taught in the classroom for more than 20 years (Farkas \& Duffett, 2010). Yet one third of the nearly half of National and State Teacher of the Year respondents who had access to professors with recent PK-12 teaching experience cited this experience as one of the top three most important contributors to their effective development at the Preservice Stage. This finding regarding the importance of accomplished teachers teaching new or struggling teachers is a theme that re-emerges throughout this report.

Elements of an Effective Clinical Practicum. As mentioned on page 8, the most important support at the Preservice Stage was access to a high-quality clinical practicum. Digging deeper, we asked the National and State Teachers of the Year specifically what aspects of the high-quality clinical practicum were most important. Top on the list was having a strong cooperating teacher, specifically in terms of the cooperating teacher's effectiveness at promoting student learning and providing adult mentorship (see Figure 4). At present, according to the National Council on Teacher Quality, only 28 percent of teacher preparation programs require that cooperating teachers be effective mentors or receive mentorship training - and even fewer programs (11 percent) require that cooperating teachers be effective at raising student achievement (Greenberg, McKee, \& Walsh, 2013). Among survey respondents, however, more than four fifths indicated that they benefited from a cooperating teacher who they viewed an effective teacher and four fifths had a cooperating teacher who they viewed as an effective adult mentor.

To aid those with the very important job of selecting cooperating teachers who have a record of raising student achievement and mentoring adults effectively, we then asked about a list of specific criteria for selecting cooperating teachers. The three most compelling criteria to National and State Teacher of the Year respondents were that the

Having opportunities to learn from multiple cooperating teachers also stood out as one of the more important contributors to the development of those who later became National and State Teachers of the Year. cooperating teacher (1) had received training for this role, (2) had more than five years of teaching experience, and (3) had taught in the same subject area as the student teacher. At least two thirds of survey respondents rated each of these characteristics as "very important." In contrast, fewer than half the respondents thought it was "very important" for the cooperating teacher to have taught in the same grade level (although 87 percent believed this background was at least "somewhat important"), to have achieved formal teacher leader recognitions, or to have served in informal teacher 
leadership capacities. Having opportunities to learn from multiple cooperating teachers also stood out as one of the more important contributors to the development of those who later became National and State Teachers of the Year.

Figure 4. Percentage of National and State Teachers of the Year Who Ranked Each Characteristic of Their Final Clinical Practicum Among the "Top Three" for Developing Their Effectiveness as a Teacher

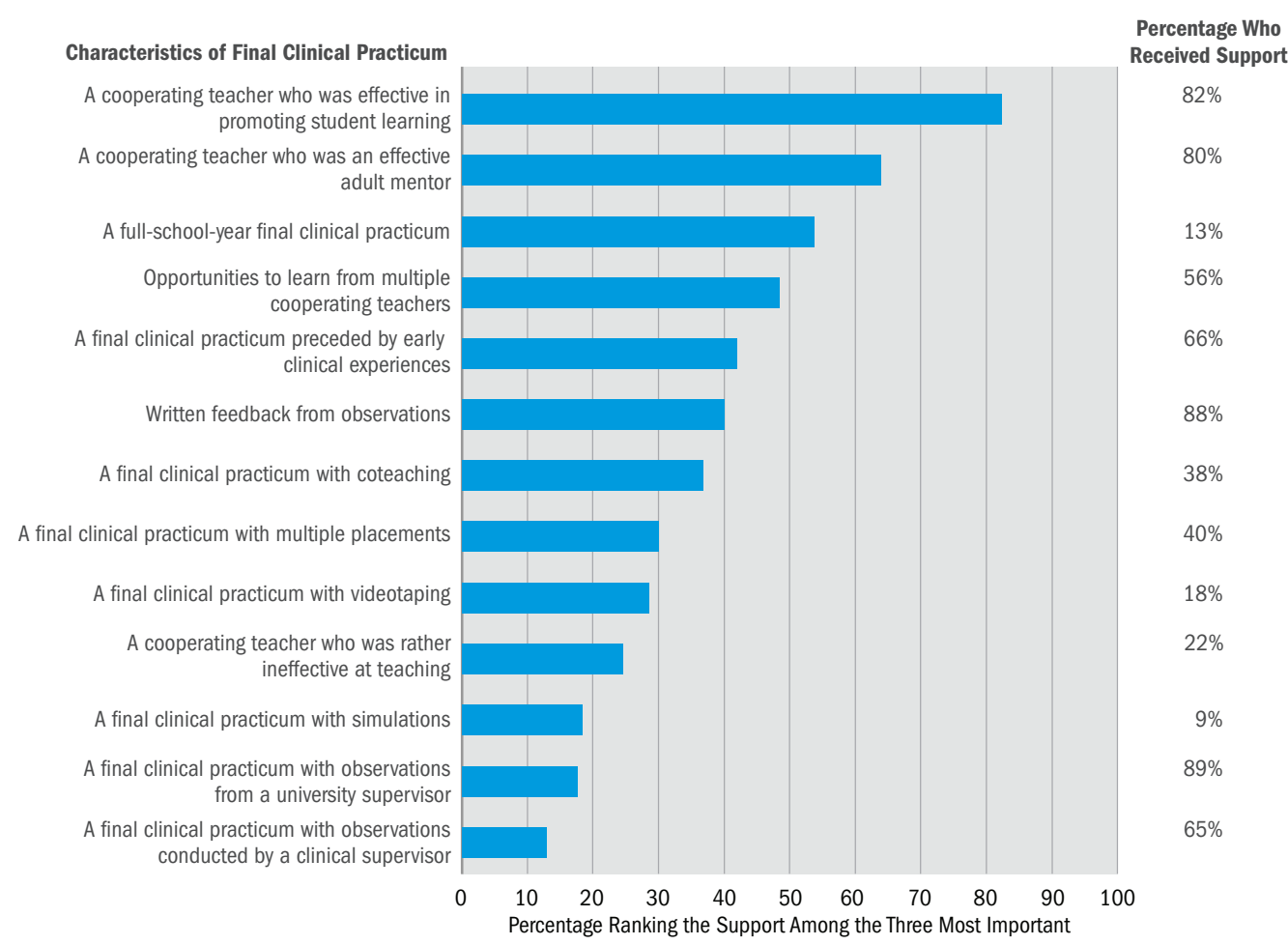

In addition to an effective cooperating teacher, survey respondents highly rated a practicum that lasts a full year. The full-year experience allows preservice teachers to see how to set up a classroom, build a community of learners, and build parent relationships_-as well as close out the school year, including conducting summative testing, analyzing results, and making recommendations for the next school year. Only 13 percent of respondents had a clinical practicum that lasted a full school year; but of those 13 percent who did experience it, 55 percent believed the yearlong experience in fact was one of the three most critical aspects of their clinical experience for developing their effectiveness as a teacher.

Of those 13 percent who did experience it, 55 percent believed the yearlong clinical practicum in fact was one of the three most critical aspects of their clinical experience for developing their effectiveness as a teacher. 


\section{Novice Stage}

We asked the National and State Teachers of the Year to think back to their first five years of teaching, consider various experiences, and indicate how those experiences affected their development during this Novice Stage. The perspectives of these excellent teachers were in line with prior studies of new teachers (Coggshall, Behrstock-Sherratt, \& Drill, 2011; Ingersoll \& Kralik, 2004; Ingersoll \& May, 2011; Johnson \& Birkeland, 2003). Most respondents indicated that they highly value the mentoring, supportive leadership, appropriate assignments for their certification, and collaborative and reflective activities that they experienced.

When asked to rate the importance of the range of Novice Stage experiences and supports (shown in Figures 5 and 6), at least 80 percent of survey respondents rated every item as "very important" or "somewhat important" to their effectiveness, with most items seen as at least "somewhat important" by more than 90 percent of respondents. However, the specific experiences and supports that respondents (who received them) rated most important during the Novice Stage were:

- Access to a mentor

- Access to a supportive principal

- Placement that aligned with their talent, training, or certification

- Collaboration with colleagues

- Common planning time

- Professional learning communities

- Self-developed professional growth plan

- Self-reflection opportunities

Each of these eight supports was seen as among the top three of those listed in Figures 5 and 6 for at least half of the respondents who benefited from them in the Novice Stage.

Bearing in mind that a large majority of survey respondents were veterans with more than 20 years of classroom experience, it was somewhat surprising to find that three quarters of the respondents had certain experiences and supports-collaboration with colleagues (73 percent), a self-developed professional growth plan (65 percent), and informal evaluations (57 percent) - that have not always been prevalent in U.S. schools.

Also of note was that in contrast to activities focused on collaboration, the three activities related to evaluations (formal evaluations of strengths and weaknesses, informal evaluations of strengths and weaknesses, and exposure to their teacher evaluation framework) were rated lower in importance for those who experienced the three activities (see Figure 6). This finding may reflect the fact that teacher evaluation systems historically have not driven professional learning, which will be revisited in the Career Stage section (see pages 15-19), although we cannot comment on the quality of survey respondents' evaluations (or other experiences) based on the data collected. 
Figure 5. Percentage of National and State Teachers of the Year Who Ranked Each Novice Stage Experience Among Their "Top Three" for Developing Their Effectiveness as a Teacher

Novice Supports for Developing Effectiveness

Received access to a mentor (assigned or informal)

Received access to a highly supportive principa

Had a school placement that aligned with my talents, training, or certificatio

Had common planning time with other teachers

Attended new-teacher workshops, trainings, or seminars on specific cross-content pedagogical issues

Participated in professional conferences

Attended new-teacher workshops, trainings, or seminars in my content area Conducted continued coursework on a master's degree

Attended an orientation program that sufficiently acquainted me with school policies and protocols from Day 1

Engaged in professional organization

Received ongoing support from my preparation program

Had a specific district support team for new teachers

Received support for new teachers from my union or association Received a reduced workload

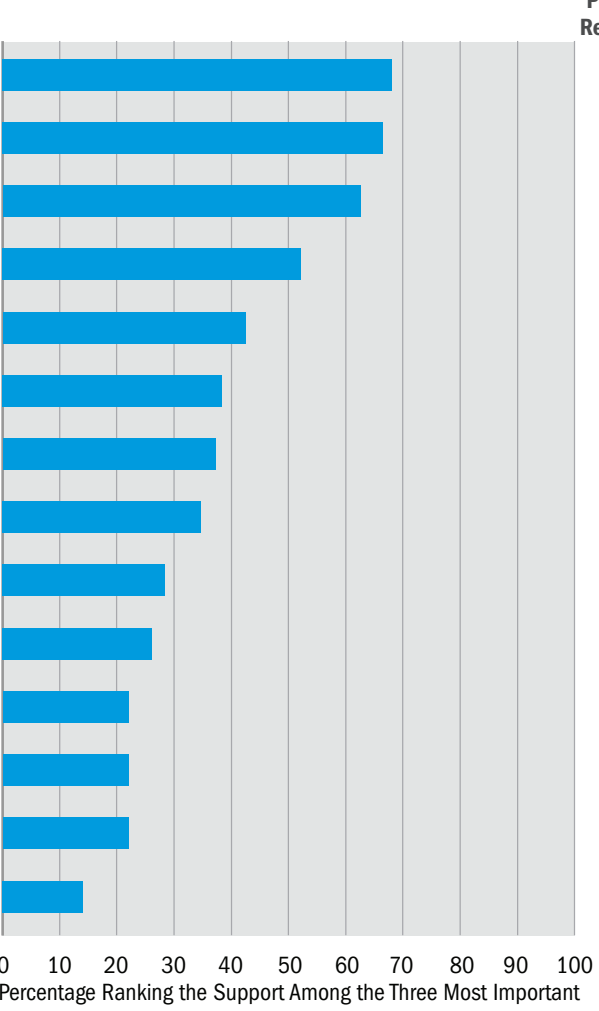

Percentage Who Received Support $55 \%$

$57 \%$

$80 \%$

$30 \%$

$40 \%$

$78 \%$

$51 \%$

$61 \%$

$50 \%$

$67 \%$

$13 \%$

$20 \%$

$20 \%$

$2 \%$ Percentage Ranking the Support Among the Three Most Important

Figure 6. Percentage of National and State Teachers of the Year Who Ranked Each Novice Stage Support Among Their "Top Three" for Strengthening Professional Learning

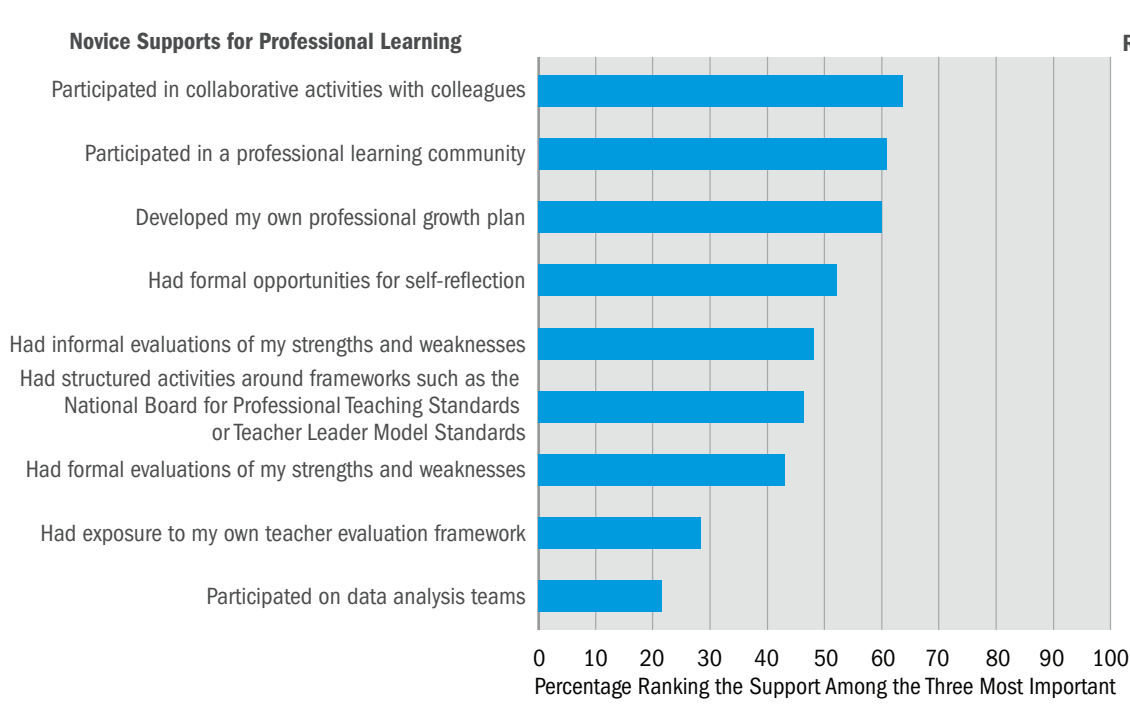

Percentage Who Received Support

$73 \%$

$28 \%$

$65 \%$

$31 \%$

$57 \%$

$9 \%$

$77 \%$

$41 \%$

$11 \%$ 
Mentoring Matters. Prior research has found that new teachers are less likely to leave the profession if they are provided with a mentor in their content area and if they participate in formal planning and collaboration with other teachers (Ingersoll \& Smith, 2004; Ingersoll \& Strong, 2011). Receiving high-quality induction and mentoring has been associated with first-year teachers showing student performance gains equivalent to those of fourth-year teachers who did not have this support (Strong, 2006). Our survey results provide further evidence that mentoring matters, with 68 percent of the 55 percent of survey respondents who had an assigned or informal mentor ranking it among their top three supports (see Figure 5).

To guide teachers and school leaders in carefully selecting mentors, we provided a list of mentor characteristics for survey respondents to rank. Only 37 percent of respondents had an assigned mentor-although this percentage is higher for those who entered the profession more recently (see "Trends to Follow: How Many Teachers Have Access to Mentors?" below). Bearing in mind this limitation in the data, all the characteristics were rated as at least "somewhat important" by 83 percent of those respondents who indicated that they did have an assigned mentor. But the mentor characteristics that stood out as having the most influence on the effectiveness of National and State Teacher of the Year respondents (both for assigned and unofficial mentors) was having mentors who modeled effective teaching practice and provided practical advice and support that was relevant to them as new teachers (see Figure 7).

\section{Trends to Follow: How Many Teachers Have Access to Mentors?}

The percentage of respondents who had an assigned mentor during their novice years (37 percent in total) was inversely correlated with the length of their teaching experience. We found:

- Twenty percent of those with 20+ years of experience had assigned mentors.

- Fifty-six percent of those with 16-20 years of experience had assigned mentors.

- Sixty-one percent of those with 11-15 years of experience had assigned mentors.

- Seventy percent of those with 6-10 years of experience had assigned mentors.

Another characteristic of mentors that was considered highly important was that the mentor be seen as a great teacher himself or herself. Slightly more than half of those who had an assigned mentor and considered that mentor as a great teacher ranked that quality as among the top three most important qualities of their mentor (see Figure 7). 
Figure 7. Percentage of National and State Teachers of the Year Who Ranked Each Characteristic of Their Assigned Mentor Among the "Top Three" Most Important Characteristics for Developing Their Effectiveness as a Teacher

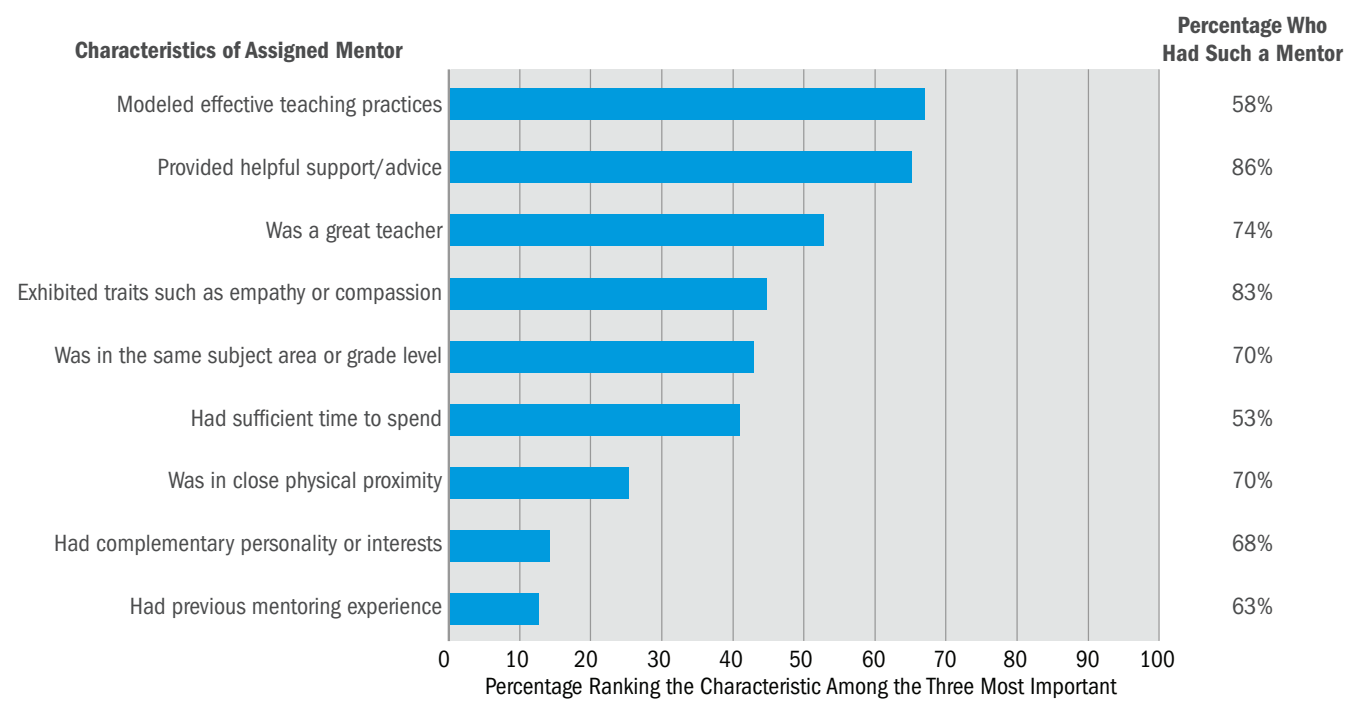

\section{Career Stage}

Some research has found that on average, a teacher's effectiveness plateaus after Year 5 (Rivkin, Hanushek, \& Kain, 2005; Rockoff, 2004). ${ }^{3}$ The surveyed National and State Teachers of the Year, however, implied in their responses that in line with the continuum of professional practice development presented in Figure 1, their effectiveness continually increased throughout the Career Stage and the Teacher Leader Stage. Whether they had been given extra supports to do so or whether they sought out such supports we cannot be certain; but we certainly can learn from the numerous ongoing professional experiences and supports that these effective teachers cited as having mattered most to their ongoing growth.

In their responses, the surveyed National and State Teachers of the Year implied that their effectiveness continually increased throughout the Career Stage and the Teacher Leader Stage.

\footnotetext{
3 Recent research, however, suggests that teacher effectiveness does in fact continue to improve throughout a teacher's career (Papay \& Kraft, 2013; Wiswall, 2013).
} 
Figure 8 illustrates the percentage of National and State Teachers of the Year who ranked each Career Stage support or experience among their top three for improving their effectiveness.

Figure 8. Percentage of National and State Teachers of the Year Who Ranked Each Career Stage Support Among the "Top Three" for Developing Their Effectiveness as a Teacher

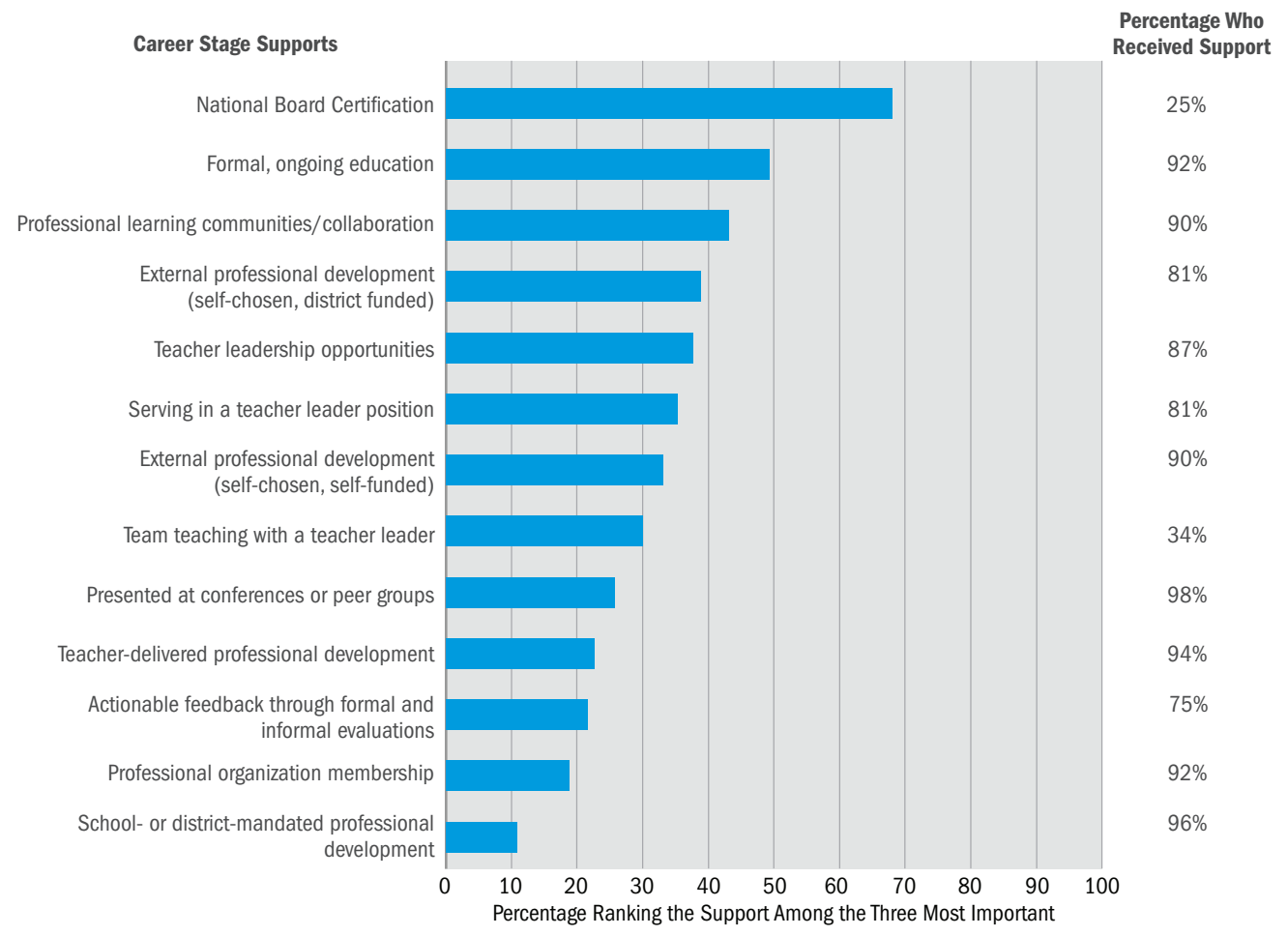

Does National Board Certification Matter? For National and State Teachers of the Year at the Career Stage as well as the Teacher Leader Stage (see pages 20-23), the process of achieving certification through the National Board for Professional Teaching Standards was seen as highly valuable by those who experienced it. As shown in Figure 8, 68 percent of those respondents who achieved National Board Certification ranked it among the three most important experiences during this Career Stage. However, this result should be considered in light of the relatively small number of National and State Teachers of the Year who achieved this recognition; although much higher than the national average of 2.7 percent (National Board for Professional Teaching Standards, 2013; National Center for Education Statistics, 2013), the percentage of National and State Teacher of the Year respondents who achieved National Board Certification was 24 percent.

Does a Master's Degree Matter? Research (Aaronson, Barrow, \& Sander, 2007; Chingos \& Peterson, 2010; Hanushek \& Rivkin, 2006) and tremendous policy dialogue_-particularly with regard to teacher pay scales-have emerged about the relevance of educational degrees for increasing teacher effectiveness. Considering the issue from the perspective of excellent 
teachers, we found that fully 92 percent of survey respondents did enroll in ongoing formal education ${ }^{4}$ as Career Stage teachers; and, indeed, half of these respondents reported that this ongoing education was among the top three most important experiences that contributed to their continued growth at this stage. This result is in line with the Novice Stage finding that of the 61 percent of respondents who conducted coursework on a master's degree in their first five years in the profession, 35 percent ranked it among their most important supports (see Figure 5).

There are numerous possible explanations for these survey findings. It may be that this group of teachers selected (or in some cases, due to their recognition, were admitted to) more relevant and high-quality courses, or that this group of highly motivated individuals made more than most teachers do of the programs they attended. Regardless of the reason, this finding draws attention to the need for further investigation of the components of master's degrees and other formal education programs that make them more or less beneficial.

Does Traditional Professional Development Matter? Teacher professional development is the subject of considerable policy dialogue, with consensus emerging that high-quality professional development should be ongoing and job-embedded (Croft, Coggshall, Dolan, Powers, \& Killion, 2010). Most respondents (80 percent to 96 percent) had experienced the full variety of more traditional professional development: school- or district-mandated, self-selected, self-funded, and provided by teachers. Further, respondents reported that they largely value these experiences. That said, although nine out of 10 respondents rated self-selected professional development as "very important," that number dropped to three out of four for their district-mandated professional development experiences.
Fully 92 percent of National and State Teachers of the Year respondents enrolled in ongoing formal education as Career Stage teachers. Half of these respondents reported that this ongoing education was among the top three most important experiences that contributed to their continued growth at this stage.

Do School Culture and Leadership Matter? We also asked survey respondents about aspects of their teaching and learning environment and resources that may have led them to become the effective teachers they are today. Two such supports that respondents considered highly important to their effectiveness were (1) a collegial, collaborative school culture and colleagues (which were ranked in the top three by 61 percent of those who had those supports) and (2) access to supportive school leadership (ranked in the top three by 50 percent of those who had that support). In total, 84 percent of respondents reported having worked in a collegial, collaborative school environment and 80 percent said they benefited from supportive school leadership. The importance of these supports

4 We did not ask respondents to specify if the education was a master's degree, a doctoral degree, or simply additional educational credits. 
In total, 84 percent of survey respondents reported having worked in a collegial, collaborative school environment and 80 percent said they benefited from supportive school leadership. is in line with the Novice Stage findings regarding the importance of a strong school principal and collaboration with colleagues (see Figure 5) and existing research that finds school principals to be the second most important school-level factor (after teachers) affecting student achievement and providing collaborative work environments as a high priority for teachers (Coggshall, Ott, Behrstock, \& Lasagna, 2010; Hallinger \& Heck, 1998; Hirsch, 2005; Leithwood, Louis, Anderson, \& Wahlstrom, 2004; Waters,

Marzano, \& McNulty, 2003). (See "Trends to Follow: How Are School Culture and Leadership Changing Over Time?” below.)

\section{Trends to Follow: How Are School Culture and Leadership Changing Over Time?}

A positive, collegial, trusting, and learning-focused culture and strong school leaders that create such a culture are found time and again to be critical not only to teachers' growth but also to their decisions to leave or remain in the profession or their school (Berry, Smylie, Fuller, 2008; Ingersoll, 2003; Kardos, Johnson, Peske, Kauffman, \& Liu, 2001). We found that the least experienced respondents (with 5-10 years of experience) were least likely to have had a strong school culture or supportive school leadership:

- Among the 24 respondents with 5-10 years of experience, only 71 percent (compared to 81 percent of the more experienced respondents) had supportive school leaders.

- Meanwhile, 63 percent of respondents with 5-10 years of experience (compared to 86 percent of the more experienced respondents) had access to a collegial, collaborative school culture and colleagues.

The source of this perceived decline in supportive school leaders and collaborative culture is certainly an important question for continued study.

Teacher Leadership. Finally, teacher leadership was seen as an important vehicle for increasing teacher effectiveness even during the Career Stage. More than one third of National and State Teacher of the Year respondents ranked having served in teacher leader positions and having had teacher leadership opportunities as among their three most important growth experiences during their Career Stage, suggesting that leadership and advancement opportunities should not be confined to recognized teacher leaders. 
Moreover (as was the case for cooperating teachers during the Preservice Stage and mentor teachers during the Novice Stage), during the Career Stage, National and State Teachers of the Year continued to value access to support from fellow teachers. Specifically, 57 percent of those who had professional development delivered by teachers cited the experience as "very important," and slightly less than a quarter ranked it among the top three most important supports in the Career Stage (see Figure 8). When we dug deeper, we found that 62 percent of respondents believed it was "very important" that external professional development be led by individuals with recent teaching experience, and 31 percent felt it was "very important" Teacher leadership was seen as an important vehicle for increasing teacher effectiveness even during the Career Stage. that their school or district professional development be led by teachers from within their school or district. Thus, this access to support from other teachers was by no means one of the most critical supports for National and state Teachers of the Year once grounded in their Career Stage-but a very useful support nevertheless.

A Note on Teacher Evaluation. Teacher evaluation is a driving force in the current education policy landscape, and a current focus is the role of evaluation in promoting professional learning. This survey did not focus on teacher evaluation, and fully half of the respondents are no longer in the classroom. But of relevance to the nationwide overhaul of teacher evaluation systems is that 25 percent of National and State Teacher of the Year respondents never received actionable feedback through formal or informal evaluations as Career Stage teachers, suggesting that evaluations are not the only way to receive valuable guidance that helps teachers grow.

Of those who did receive such evaluation feedback, this support ranked third lowest on the list of their most important experiences during the Career Stage. A similar pattern was evident in the Novice Stage, with supports related to evaluations ranking lower than others (see Figure 6). To be sure, 90 percent of those who received evaluation feedback during the Career Stage still believed it was "very helpful" or "somewhat helpful" for them in becoming effective instructors. And, of course, the evaluations experienced by National and State Teacher of the Year respondents who have not been part of the nationwide overhaul of teacher evaluation during the last few years likely were quite different from the evaluation systems that are being designed today with greater attention to their link to professional learning (Coggshall, Rasmussen, Colton, Milton, \& Jacques, 2012). Still, these results suggest that further investigation is needed on how to ensure that evaluation feedback and other evaluation activities do promote teacher growth - as well as whether there are other investments in professional learning that are more important than evaluations for achieving professional learning objectives. 


\section{Teacher Leader Stage}

The National and State Teachers of the Year are a unique group of teacher leaders. They have been recognized for their skills in classroom practice; they received extensive training in policy and advocacy; and, in many cases, they participated in leadership activities. These highly effective teachers have served on think-tank panels and policy

Even after receiving recognition as a National or State Teacher of the Year, these already excellent teachers continued to enhance their skills and knowledge, often while simultaneously helping others do the same. The professional experiences that the National and State Teachers of the Year ranked as among the most important experiences for further fueling teacher leaders' effectiveness in the classroom were (1) providing formal coaching or mentoring while remaining a classroom teacher, (2) facilitating professional development, and (3) becoming a mentor or coach. task forces, written articles and blog posts, served in leadership positions while remaining in the classroom, and shared their expertise as teacher leaders with policymakers at all levels of governance. But, as with the Career Stage, we found that in the Teacher Leader Stage, these already excellent teachers continued to enhance their skills and knowledge, often while simultaneously helping others do the same.

Again, bearing in mind that respondents represent a more veteran cohort that may not reflect the experiences of most teacher leaders today, of note is that their opportunities for school-level teacher leadership appear to have been somewhat restricted to the more traditional roles of teacher leadership: professional learning facilitation, conference presentations, and informal leadership roles within their schools. In contrast, formal school- or district-level leadership roles emerged as less prevalent (see "Where Are the National and State Teachers of the Year Leading?" on page 22). The insufficiency of opportunities to lead also is borne out by research examining roles for teacher leaders in both formal and informal capacities (Curtis, 2013; TNTP, 2013).

Enhancing Effectiveness Efficiently. Figure 9 indicates the professional experiences that the National and State Teachers of the Year ranked as among the most important experiences for further fueling teacher leaders' effectiveness in the classroom:

(1) providing formal coaching or mentoring while remaining a classroom teacher, (2) facilitating professional development, and (3) becoming a mentor or coach. 
Figure 9. Percentage of National and State Teachers of the Year Who Ranked Each Experience Among the "Top Three" for Developing Their Effectiveness During the Teacher Leader Stage

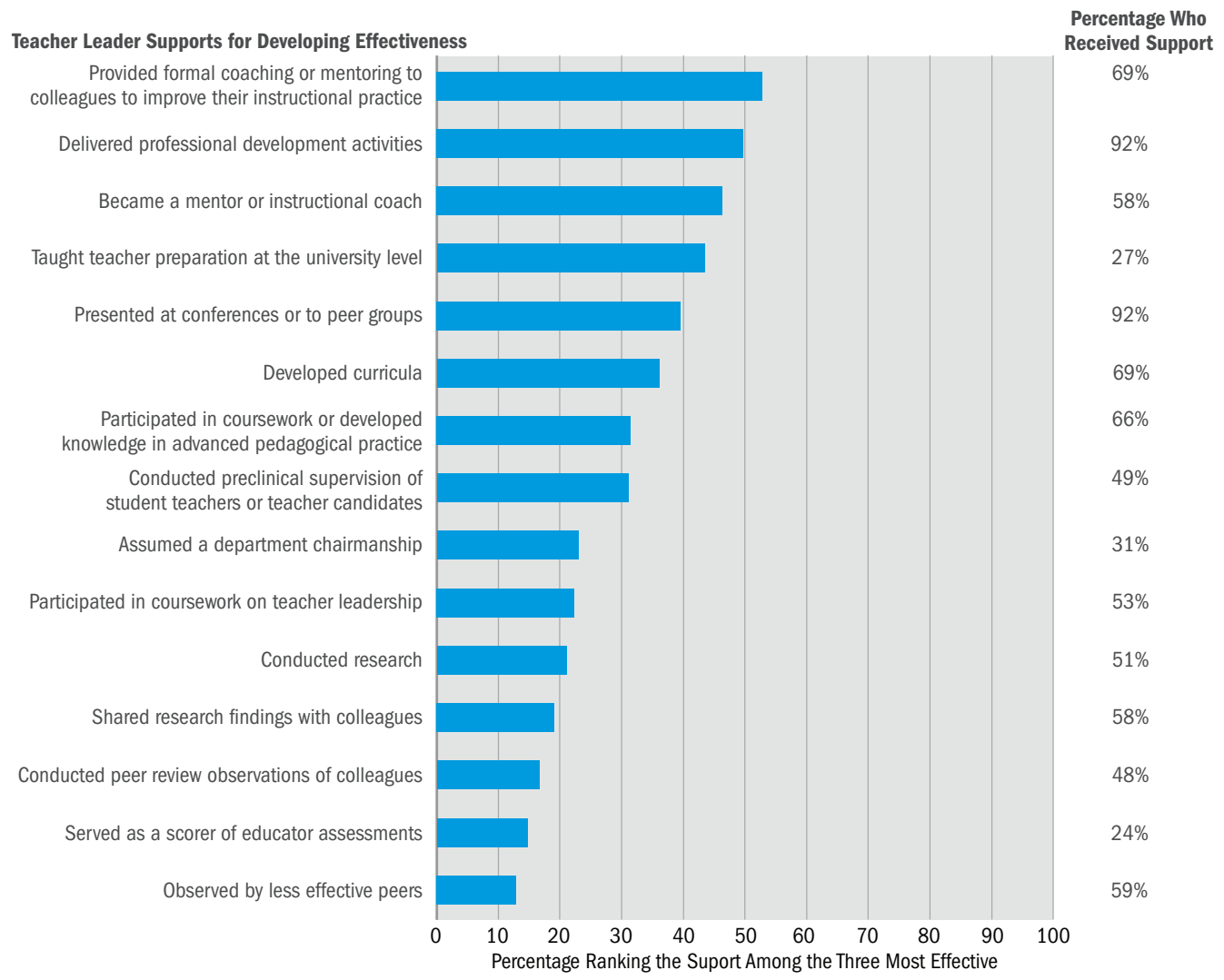

Thus, the two-way experience of serving as a teacher mentor, coach, or professional development facilitator not only improved the effectiveness of the teachers they served (as discussed on page 14) but also was one of the most valuable supports for the teacher leaders themselves. Likewise, as noted on page 10, having professors with recent PK-12 experience was seen as among the top three most important preservice supports by one third of survey respondents; meanwhile, although only 27 percent of respondents had the experience of teaching preservice teachers, that experience was highly rated for further strengthening the effectiveness of those who did, with 44 percent ranking it among their top three supports (see Figure 9).

In some schools and districts, the expertise of teacher leaders often is overlooked or underutilized because of the common preference for The two-way experience of serving as a teacher mentor, coach, or professional development facilitator not only improved the effectiveness of the teachers they served but also was one of the most valuable supports for the teacher leaders themselves. external sources of professional development and guidance. Efforts to build the capacity of emerging in-school or in-district teacher leaders may be constrained by such practices. Instead, enabling teacher leaders to assume these mutually beneficial yet underutilized roles may be a highly valuable and efficient way to allocate school resources for improving teacher effectiveness. 


\section{Where Are the National and State Teachers of the Year Leading?}

The National and State Teachers of the Year indicated that upon becoming a teacher leader, their most and least common leadership roles and professional learning supports were as follows:

- Ninety-two percent facilitated professional development.

- Ninety-two percent presented at conferences or to peer groups.

- Eighty-nine percent had experience serving on national, state, or local forums, workshops, or conferences.

- Eighty-five percent met with policymakers.

- Eighty-three percent organized whole-school, whole-grade-level, or whole-team projects.

- Eighty-two percent had informal leadership roles in improving colleagues' instructional practice.

- Eighty-one percent served on school or district leadership teams.

- Seventy-five percent served on national, state, or local education policy and/or public policy committees, task forces, or think tanks.

- Sixty-nine percent provided formal coaching or mentoring to colleagues.

- Sixty-nine percent conducted curriculum development.

- Sixty-six percent developed collaborative projects with the community.

- Sixty-six percent took coursework or developed knowledge in advanced pedagogical practice.

- Fifty-nine percent were observed by less effective peers.

- Fifty-eight percent were instructional coaches or mentors.

- Fifty-eight percent shared research findings with colleagues.

- Fifty-three percent took coursework on teacher leadership.

- Fifty-three percent had formal leadership roles where they were jointly accountable for colleagues' student outcomes while continuing to teach.

- Fifty percent conducted research.

- Forty-nine percent conducted preclinical supervision of student teachers or teacher candidates.

- Forty-eight percent conducted peer review observations of colleagues.

- Forty percent took coursework on adult learning.

- Thirty-three percent served as union or association leaders, negotiating team members, board members, committee members, or delegates to the assembly.

- Thirty-one percent assumed department chairmanships.

- Thirty percent had a role where they reached more students than normal by using blended learning.

- Twenty-seven percent had formal leadership roles where they were jointly accountable for colleagues' student outcomes but were not continuing to teach.

- Twenty-seven percent taught teacher preparation at the university level.

- Twenty-four percent had roles where they reached more students than normal by leading a teaching team.

- Twenty-four percent served as scorers of educator assessments. 
Serving as a National or State Teacher of the Year provided the survey respondents with many opportunities for leadership. These opportunities typically are not—but perhaps should be-provided to many more outstanding teachers. As noted in previous sections of this report, it is important to keep in mind that all the experiences we asked about were viewed as important for continually strengthening practice during the Teacher Leader Stage. Yet, most important were supporting new or struggling teachers as mentors and coaches and working with colleagues on professional learning activities.

Conducting Research. A final observation pertains to teacher leaders conducting research. About half of the surveyed National and State Teachers of the Year did conduct research (see Figure 9). Among this group, 38 percent indicated that the experience was "very important" for increasing their effectiveness (and a further 57 percent believed it was "somewhat important"). Similar to countries such as Finland and China, which have high-performing students and which continually provide opportunities for teachers to conduct research as part of their practice, NNSTOY intentionally engages State Teachers of the Year as teacher researchers in all About half of the surveyed National and State Teachers of the Year did conduct research. Among this group, 38 percent indicated that the experience was "very important" for increasing their effectiveness (and a further 57 percent believed it was "somewhat important"). research projects (Organisation for Economic Co-operation and Development, 2011). We hope that collaborative studies such as this one become more prevalent as an avenue to strengthen teacher leadership, practice, research, and policy.

\section{Considerations}

The results of this exploratory survey shed light on many experiences and supports that helped award-winning teachers grow and improve over the course of their career. In light of the survey results presented in this report, we offer the following considerations for policymakers and education leaders.

- Consideration 1: Support Teachers Teaching Teachers. How can we create more opportunities to connect new and struggling teachers with teacher leaders who can help them improve? This potentially efficient approach to professional learning was seen by National and State Teachers of the Year as elevating the effectiveness of both the learner and the instructor. Such opportunities should span the career continuum, with access to teacher leaders through preparation coursework and clinical experiences, mentorship programs, and ongoing professional learning activities. Education Secretary Duncan's recently launched "Teach to Lead" initiative aims to facilitate wider use of such teacher leadership roles, while prior NNSTOY reports such as Re-Imagining Teaching: Five Structures to Transform the Profession (Bassett et al., 2013) and Creating Sustainable Teacher Career Pathways: A 21st Century Imperative (Natale, Bassett, Gaddis, \& McKnight, 2013) provide insights, ideas, and inspiration from other countries and other professions. Policymakers 
and education leaders at all levels should work with teacher leaders to design, implement, and promote these opportunities.

- Consideration 2: Act on What We Know Works. This survey confirmed the findings of many previous studies - namely, the National and State Teacher of the Year respondents agreed about the importance of the preservice clinical experience, mentors, placement aligned with their license and expertise, collaboration with colleagues, strong school leadership, opportunities for reflection, self-selection of professional development that is grounded in day-to-day practice, and leadership opportunities. Policymakers should consider how to support and incentivize school districts, teacher and principal preparation programs, and other stakeholders to develop partnerships that put these critical supports in place for every teacher. For example, policymakers could incentivize partnerships among preparation programs, professional development providers, schools, and districts to set priorities and allocate resources in ways that strengthen and lengthen clinical placements for teacher candidates; structure the school day strategically; and hire, place, and assign responsibilities to staff wisely.

- Consideration 3: Reconsider the Dialogue. The national narrative, supported by previous research, suggests that ongoing formal education (particularly master's degrees) and teacher experience ${ }^{5}$ do not affect teacher effectiveness. This survey suggests that more investigation into and dialogue about this issue may be warranted. For many possible reasons, the surveyed National and State Teachers of the Year believe that their ongoing formal courses contributed to their growth as effective teachers. More nuance may be beneficial in the policy discussion and development on these topics. In particular, education leaders should give more consideration to the particular aspects of ongoing formal education and professional development that are most important and then determine how best practice in continuing education and training can be brought to scale to benefit all teachers.

- Consideration 4: Prioritize and Improve Teacher Development on Many Fronts. This survey focused on pinpointing which experiences and supports across the teacher career continuum most influenced the instructional excellence of National and State Teachers of the Year; but every experience and support was viewed as important by a large majority of survey respondents-and even as among the most important by some respondents. Certain experiences (such as a yearlong clinical practicum and National Board Certification) were seen as highly valuable by those who had undertaken such experiences, but only a small proportion of respondents had undertaken those experiences. Other supports (such as a high-quality clinical practicum and effective cooperating teachers at the Preservice Stage; and opportunities for collaboration, the development of professional growth plans, and informal evaluations of strengths and weaknesses at the Novice Stage) were highly prevalent among National and State Teachers of the Year, raising the question as to

5 More recent research, it should be noted, has called this finding into question (Papay \& Kraft, 2013; Wiswall, 2013). 
whether these early supports are correlated with effectiveness. Still other supports (such as school- or district-mandated professional development) were viewed as comparatively less beneficial, but they raised the question of how high-quality these professional learning experiences were. There is a need for more research that digs deeper into the characteristics of each of the professional experiences and supports covered in this survey that might make those experiences and supports more or less useful to teachers as they strive to improve student outcomes.

Policymakers and education leaders, therefore, should not treat these data as the answer but rather as a guide to collaboratively determine in their context both which experiences and supports should be funded and prioritized and which experiences and supports can be delivered more effectively. The GTL Center's companion Discussion Starter Tool (which is available at http://www.gtlcenter.org/productsresources/study-teacher-perspectives-factors-influencing-effectiveness) aims to begin discussions of this nature.

\section{Next Steps}

As the first comprehensive national survey of effective teachers' views on developing teacher effectiveness, this exploratory study contributes to the current body of teacher effectiveness research both in its design and outcomes. Because the National and State Teacher of the Year respondents represent a more veteran population than the teaching force at large, the findings-while limited in certain ways-offer a unique breadth of perspective on how these teachers got from good to great as they moved across the career continuum. From high-quality preservice clinical experiences to opportunities for teacher leaders to help less effective teachers improve, our survey findings provide guidance to leaders about the experiences and supports that matter. Yet we do not see this report as a definitive guide; rather, it marks the beginning of more dialogue and more research to inform more smart policy that meaningfully engages teachers each step of the way.

Each professional experience and support discussed in this report requires further unpacking to determine whether it is inherently important or unimportant, whether certain characteristics make it more or less important to effective teachers, and how it can be made to be as helpful as possible. In addition, similar surveys could be used with a larger sample of effective teachers-particularly those teachers who have benefitted from each experience or support more recently as well as those teachers who are experiencing developing approaches aimed at increasing teacher effectiveness through evaluation feedback and other present-day reforms. As the current study partners and new partners continue to address these questions, teachers' expertise should be centrally incorporated in the research. And as the research informs our policies, so too should teachers' voices be centrally present. 


\section{References}

Aaronson, D., Barrow, L., \& Sander, W. (2007). Teachers and student achievement in the Chicago public high schools. Journal of Labor Economics, 25(1), 95-136.

Bassett, K., Grossman, T., Allan, P., Allen, M., Cook, S., \& Olney, M. A. (2013). Re-imagining teaching: Five structures to transform the profession. Washington, DC: National Network of State Teachers of the Year. Retrieved from http://www.nnstoy.org/download/Re-Imagining \%20Teaching_10-4-2013.pdf

Behrstock-Sherratt, E., Rizzolo, A., Laine, S., \& Friedman, W. (2013). Everyone at the table: Engaging teachers in evaluation reform. San Francisco, CA: Jossey-Bass.

Berry, B., Smylie, M., \& Fuller, E. (2008). Understanding teacher working conditions: A review and look to the future. Carrboro, NC: Center for Teaching Quality. Retrieved from http://www.teachingquality. org/sites/default/files/Understanding\%20Teacher\%20Working\%20Conditions-\%20A\%20Review \%20and\%20Look\%20to\%20the\%2OFuture.pdf

Bosso, D. (2014). This is what I am: Teacher morale, motivation, and professional identity in the context of education reform. Dissertation in preparation.

Boyd, D., Grossman, P., Lankford, J., Loeb, S., \& Wyckoff, J. (2009). Teacher preparation and student achievement. Educational Evaluation and Policy Analysis, 31(4), 416-440. Retrieved from http://cepa.stanford.edu/sites/default/files/Preparation\%20and\%20Achievement.pdf

Center on Great Teachers and Leaders \& National Network of State Teachers of the Year. (2014). Survey results: Teacher perspectives on factors influencing effectiveness. Washington, DC: Authors.

Chingos, M., \& Peterson, P. (2010). It's easier to pick a good teacher than to train one: Familiar and new results on the correlates of teacher effectiveness (Working Paper). Cambridge, MA: Harvard University, Program on Education and Policy Governance. Retrieved from http://www.hks. harvard.edu/pepg/PDF/Papers/2010-22_PEPG_Chingos_Peterson.pdf

Coggins, C., Peske, H., \& McGovern, K. (2013). Learning from the experts: Teacher leaders on solving America's education challenges. Cambridge, MA: Harvard Education Press.

Coggshall, J. G., Bivona, L., \& Reschly, D. (2012). Evaluating the effectiveness of teacher preparation programs for support and accountability. Washington, DC: National Comprehensive Center for Teacher Quality. Retrieved from http://www.gtlcenter.org/sites/default/files/docs/TQ_RandP_ BriefEvaluatingEffectiveness.pdf

Coggshall, J. G., Behrstock-Sherratt, E., \& Drill, K. (2011). Workplaces that support high-performing teaching and learning: Insights from Generation $Y$ teachers. Naperville, IL: American Institutes for Research; Washington, DC: American Federation of Teachers. Retrieved from http://www.air. org/sites/default/files/downloads/report/GenerationY_Workplaces_That_Support_Teaching_ and_Learning_0.pdf

Coggshall, J. G., Ott, A., Behrstock, E., \& Lasagna, M. (2010). Retaining teacher talent: The view from Generation Y. Naperville, IL: Learning Point Associates; New York, NY: Public Agenda. Retrieved from http://www.learningpt.org/expertise/educatorquality/genY/SupportingTeacherEffectiveness/ Gen\%20Y\%20report.pdf

Coggshall, J. G., Rasmussen, C., Colton, A., Milton, J., \& Jacques, C. (2012). Generating teaching effectiveness: The role of job-embedded professional learning in teacher evaluation (Research \& Policy Brief). Washington, DC: National Comprehensive Center for Teacher Quality. Retrieved from http://www.gtlcenter.org/sites/default/files/docs/GeneratingTeachingEffectiveness.pdf 
Croft, A., Coggshall, J., Dolan, M., Powers, E., \& Killion, J. (2010). Job-embedded professional development: What it is, who is responsible, and how to get it done well. Washington, DC: National Comprehensive Center for Teacher Quality. Retrieved from http://www.gtlcenter.org/ sites/default/files/docs/JEPD\%20Issue\%20Brief.pdf

Curtis, R. (2013). Finding a new way: Leveraging teacher leadership to meet unprecedented demands. Washington, DC: The Aspen Institute. Retrieved from http://www.aspendrl.org/portal/browse/ DocumentDetail?documentld=1574\&download

Darling-Hammond, L. (2000). Teacher quality and student achievement. Education Policy Analysis Archives, 8, 1-44. Retrieved from http://epaa.asu.edu/ojs/article/view/392/515

Drill, K., Miller, S., \& Behrstock-Sherratt, E. (2013). Teachers' perspectives on educational research. Brock Education: A Journal of Educational Research and Practice, 23(1), 3-17. Retrieved from http://brock.scholarsportal.info/journals/brocked/home/article/viewFile/350/228

Dreyfus, H. L., \& Dreyfus, S. E. (1986). Mind over machine: The power of human intuition and expertise in the age of the computer. Oxford, United Kingdom: Basil Blackwell.

Farkas, S., \& Duffett, A. (2010). Cracks in the ivory tower: The views of education professors circa 2010. New York, NY: The FDR Group; Washington, DC: Thomas B. Fordham Institute. Retrieved from http://edexcellence.net/sites/default/files/publication/pdfs/Cracks\%20In\%20The\%20 Ivory\%20Tower\%20-\%20Sept\%202010_8.pdf

Goldring, R., Gray, L., \& Bitterman, A. (2013). Characteristics of public and private elementary and secondary school teachers in the United States: Results from the 2011-12 Schools and Staffing Survey (NCES 2013-314). Washington, DC: National Center for Education Statistics. Retrieved from http://nces.ed.gov/pubs2013/2013314.pdf

Greenberg, J., McKee, A., \& Walsh, K. (2013). Teacher prep review: A review of the nation's teacher preparation programs. Washington, DC: National Council on Teacher Quality. Retrieved from http://www.nctq.org/dmsView/Teacher_Prep_Review_2013_Report

Hallinger, P., \& Heck, R. (1998). Exploring the principal's contribution to school effectiveness: 1980-1995. School Effectiveness and School Improvement, 9(2), 157-191.

Hanushek, E. A., \& Rivkin, S. G. (2006). Teacher quality. In E. A. Hanushek \& F. Welch (Eds.), Handbook of the economics of education (Vol. 2, pp. 1052-1078). New York, NY: Elsevier. Retrieved from http://hanushek.stanford.edu/sites/default/files/publications/ Hanushek\%2BRivkin\%202006\%20HbEEdu\%202.pdf

Hart, P. D. (2008). Teaching as a second career. Princeton, NJ: Woodrow Wilson National Fellowship Foundation.

Hill, H. C., Rowan, B., \& Ball, D. L. (2005). Effects of teachers' mathematical knowledge for teaching on student achievement. American Educational Research Journal, 42(2), 371-406.

Hirsch, E. (2005). Listening to the experts: A report on the 2004 South Carolina teacher working conditions survey. Chapel Hill, NC: Southeast Center for Teaching Quality. Retrieved from http://www.teachingquality.org/sites/default/files/Listening\%20to\%20the\%20Experts-\%20 A\%20Report\%20on\%20the\%202004\%20South\%20Carolina\%20Teacher\%20Working\%20 Conditions\%20Survey.pdf

Ingersoll, R. M. (2003). Is there really a teacher shortage? (Document R-03-4). Seattle: University of Washington, Center for the Study of Teaching and Policy. Retrieved from http://depts.washington. edu/ctpmail/PDFs/Shortage-RI-09-2003.pdf 
Ingersoll, R., \& Kralik, J. M. (2004). The impact of mentoring on teacher retention: What the research says (Research Review). Denver, CO: Education Commission of the States. Retrieved from http://www.gse.upenn.edu/pdf/rmi/ECS-RMI-2004.pdf

Ingersoll, R., \& May, H. (2011). Recruitment, retention, and the minority teacher shortage (Research Report \#RR-69). Philadelphia: University of Pennsylvania, Consortium for Policy Research in Education; Santa Cruz: University of California, Center for Educational Research in the Interest of Underserved Students. Retrieved from http://www.cpre.org/sites/default/files/ researchreport/1221_minorityteachershortagereportrr69septfinal.pdf

Ingersoll, R. M., \& Smith, T. M. (2004). Do teacher induction and mentoring matter? NASSP Bulletin, 88(638), 28-40.

Ingersoll, R. M., \& Strong, M. (2011). The impact of induction and mentoring programs for beginning teachers: A critical review of the research. Review of Educational Research, 81(2), 201-233.

Kardos, S., Johnson, S. M., Peske, H., Kauffman, D., \& Liu, E. (2001). Counting on colleagues: New teachers encounter the professional cultures of their schools. Educational Administration Quarterly, 37(2), 250-290.

Johnson, S. M., \& Birkeland, S. (2003). Pursuing a "sense of success": New teachers explain their career decisions. American Educational Research Journal, 40, 581-617. Retrieved from http://aer.sagepub.com/content/40/3/581.full.pdf

Leithwood, K., Louis, K., Anderson, S., \& Wahlstrom, K. (2004). How leadership influences student learning (Review of Research). New York, NY: The Wallace Foundation. Retrieved from http://www.wallacefoundation.org/knowledge-center/school-leadership/key-research/ Documents/How-Leadership-Influences-Student-Learning.pdf

Levine, A. (2006). Educating school teachers. Washington, DC: The Education Schools Project. Retrieved from http://www.edschools.org/pdf/Educating_Teachers_Report.pdf

Markow, D., \& Martin, S. (2005). The Metlife survey of the American teacher: Transitions and the role of supportive leadership. New York, NY: Metlife. (ERIC Document Reproduction Service No. ED488837). Retrieved from http://files.eric.ed.gov/fulltext/ED488837.pdf

McCaffrey, J. R., Lockwood, D. F., Koretz, D. M., \& Hamilton, L. S. (2003). Evaluating value-added models for teacher accountability [Monograph]. Santa Monica, CA: RAND Corporation. Retrieved from http://www.rand.org/content/dam/rand/pubs/monographs/2004/RAND_MG158.pdf

Natale, C. F., Bassett, K., Gaddis, L., McKnight, K. (2013). Creating sustainable teacher career pathways: A 21st century imperative. Washington, DC: National Network of State Teachers of the Year \& Pearson Research and Innovation Network. Retrieved from http://www.nnstoy.org/ download/Final\%20updated\%20Research\%20Report.pdf

National Board for Professional Teaching Standards. (2013, January 8). Number of Board-Certified teachers tops 100,000 as new studies show significant gains in student achievement [Press release]. Retrieved from http://www.nbpts.org/nbpts-2013-01-08-nbct-student-achievement

National Center for Education Statistics. (2013). Fast facts: Teacher trends [Website]. Retrieved from https://nces.ed.gov/fastfacts/display.asp?id=28

National Research Council. (2010). Preparing teachers: Building evidence for sound policy. Washington, DC: National Academies Press.

Organisation for Economic Co-operation and Development. (2011). Building a high-quality teaching profession: Lessons from around the world. Paris, France: OECD Publishing. Retrieved from http://asiasociety.org/files/lwtw-teachersummit.pdf 
Papay, J. P., \& Kraft, M. A. (2013). Productivity returns to experience in the teacher labor market: Methodological challenges and new evidence on long-term career improvement (Working Paper). Cambridge, MA: Harvard University. Retrieved from http://scholar.harvard.edu/files/mkraft/ files/papay_kraft_-_rte_may_2013_-_v2.pdf

Rivkin, G., Hanushek E., \& Kain, J. (2005). Teachers, schools, and academic achievement. Econometrica, 73(2), 417-458.

Rockoff, J. E. (2004). The impact of individual teachers on student achievement: Evidence from panel data. American Economic Review, 94(2), 247-252.

Rowan, B., Correnti, R., \& Miller, R. J. (2002). What large-scale survey research tells us about teacher effects on student achievement: Insights from the Prospects study of elementary schools. Teachers College Record, 104, 1525-1567.

Strong, M. (2006). Does new teacher support affect student achievement? (Research Brief). Santa Cruz, CA: New Teacher Center. Retrieved from http://www.newteachercenter.org/sites/default/ files/ntc/main/resources/BRF_DoesNewTeacherSupportAffectStudentAchievement.pdf

TNTP. (2013). Perspectives of irreplaceable teachers: What America's best teachers think about teaching. Washington, DC: Author. Retrieved from http://tntp.org/assets/documents/TNTP_ Perspectives_2013.pdf

U.S. Department of Education. (2011, September 30). Education department proposes reforms to improve teacher preparation programs and better prepare educators for classroom success [Press release]. Retrieved from http://www.ed.gov/news/press-releases/education-departmentproposes-reforms-improve-teacher-preparation-programs-and-b

Waters, T., Marzano, R., \& McNulty, B. (2003). Balanced leadership: What 30 years of research tells us about the effect of leadership on student achievement. Aurora, CO: Mid-continent Regional Educational Laboratory. Retrieved from http://www.mcrel.org/ /media/Files/McREL/ Homepage/Products/01_99/prod82_BalancedLeadership.ashx

Wiswall, M. (2013). The dynamics of teacher quality. Journal of Public Economics, 100, 61-78.

Wright, S. P., Horn, S. P., \& Sanders, W. L. (1997). Teachers and classroom context effects on student achievement: Implications for teacher evaluation. Journal of Personnel Evaluation in Education, 11, 57-67. 


\section{Appendix. Methodology for the Survey}

\section{Overview}

The initial research questions and impetus for this exploratory study came from the nonprofit organization National Network of State Teachers of the Year (NNSTOY), but the study has been a collaborative effort among the seven partner organizations: American Association of Colleges of Teacher Education, Center on Great Teachers and Leaders (GTL Center) at American Institutes for Research (AIR), Council for the Accreditation of Educator Preparation, Council of Chief State School Officers, National Council on Teacher Quality, National Education Association, and NNSTOY. Each of these organizations has deep content expertise and experience conducting research studies. Throughout the entire process, the survey also has benefited from the involvement of National and State Teachers of the Year who are currently practicing teachers.

\section{Development of the Survey instrument}

On May 8,2013 , the seven partner organizations met to lay the groundwork for the survey design. Together, they defined the stages of the teacher career continuum, ${ }^{6}$ conducted initial brainstorming for survey content, and confirmed the roles and responsibilities of each partner. In particular, the partners determined the responsibilities for using the group's collective expertise as researchers, practitioners, and policy analysts to inform the survey design. From May 30 to June 17, 2013, the partner organizations collaborated to develop the categories of professional experiences and supports for the teacher continuum stage in which their organization holds greatest expertise. Table A1 indicates the organizations that developed survey content for the teacher continuum stages.

${ }^{6}$ Initially, content was developed separately for a Novice Stage and an Advanced Beginner Stage. Because of overlap in the relevant professional experiences and supports, these two stages were collapsed into the Novice Stage. 
Table A1. Survey Assignments for the Teacher Continuum Stages

\begin{tabular}{ll} 
Stage & Organizations That Developed Survey Content \\
Preservice & $\begin{array}{l}\text { American Association of Colleges of Teacher Education } \\
\text { Council for the Accreditation of Educator Preparation } \\
\text { National Council on Teacher Quality }\end{array}$ \\
\hline Novice & $\begin{array}{l}\text { American Association of Colleges of Teacher Education } \\
\text { Council for the Accreditation of Educator Preparation } \\
\text { National Education Association }\end{array}$ \\
\hline Career & National Council on Teacher Quality \\
& National Education Association \\
& National Network of State Teachers of the Year \\
\hline Teacher Leader & Council of Chief State School Officers \\
& National Network of State Teachers of the Year \\
\hline
\end{tabular}

Partners were asked to focus the survey content development on the full range of professional experiences and supports that (1) increase teacher content knowledge;

(2) enable teacher skill acquisition and improvement (i.e., improve pedagogy); and

(3) increase teacher responsibility for student success.

On June 25, 2013, during the Education Commission of the States meeting in St. Louis, a two-hour focus group was held with 12 members of the current cohort of recently appointed State Teachers of the Year. These 12 participating teachers represented a range of subject areas, geographic locations, and years of experience. The focus group protocol included questions and probes about the 163 professional experiences and supports that the partner organizations developed to inform the survey items as well as shared reactions to the proposed survey language. For example, focus group participants reacted negatively to the final continuum stage being called "expert." Believing that they themselves were still not "expert," they suggested the alternative term "teacher leader" for the final stage in the career continuum. Focus group participants also were asked about the useful aspects of the various experiences and supports they had from preservice training through the current day that increased their effectiveness with their students.

Based on the responses of these teachers to the content developed by the partner organizations, staff at the GTL Center, in collaboration with NNSTOY, created draft survey items. On July 15, 2013, a second two-hour focus group was held during NNSTOY's annual convening in Minneapolis. Another group of 12 State Teachers of the Year-representing a range of subject areas, geographic locations, and years of experience-participated in the focus group. This second focus group walked the State Teacher of the Year participants through the draft survey items to identify areas where clarification was needed or where any critical content was missing. 
Following the second focus group, the core team from NNSTOY and the GTL Center revised the draft survey items and submitted the items to AIR's Center for Survey Methods (CSM). Methodologists at CSM reviewed the survey and provided comments aimed at clarifying the meaning and purpose of the items, specifying reference periods, adding instructions, and reducing respondent burden. Next, each of the partner organizations provided input into the revised survey items, with a focus on their assigned continuum stage, and these suggestions were incorporated into the survey. Policy experts from Public Impact also offered input on the draft survey. The final survey consisted of sets of items for each one of the four teacher continuum stages and a section of background information. (The survey instrument and survey results are available online at http://www.gtlcenter.org/ products-resources/study-teacher-perspectives-factors-influencing-effectiveness.)

After the survey was professionally edited, survey methodologists from American Institutes for Research created skip-logic specifications for an online administration. Using the online survey software Vovici 6 , the instrument was programmed and tested. The survey testing process included the evaluation of survey length, and it was estimated to take approximately 45 minutes to complete.

\section{Data Collection}

CSM methodologists were responsible for survey administration. NNSTOY provided CSM with a participant list that included names and e-mail addresses of 763 PK-12 teachers nationwide who had been recognized as a State Teacher of a Year between the mid-1970s and 2013. ${ }^{7}$ Names with invalid e-mail addresses were deleted, and the population was narrowed to 755 teachers. No sampling was performed. Data collection efforts began on November 5, 2013, when NNSTOY sent the 755 participants a prenotice e-mail informing them of the upcoming survey. Two days later, on November 7, 2013, CSM methodologists sent e-mail invitations with a respondent-specific link to the survey. Afterward, CSM methodologists sent four follow-up e-mails to nonrespondents on the following dates: November 15, 20, 22, and 26. Data collection ended on December 1, 2013.

\section{Case Disposition, Response Rates, and Data Review}

A survey was considered complete if the respondent answered items up to at least Item 35, which concludes the second continuum stage section, Novice and Advanced Beginner Stage. ${ }^{8}$ Of the 755 individuals who were invited to participate in the survey, 298 respondents completed it and 39 started the survey but did not finish it. Of these 39 individuals, 13 reached the cutoff point to be considered "completed." As a result, in the final disposition of cases, there were 311 complete cases out of a total eligible of 755 , resulting in a 41.2 percent response rate.

\footnotetext{
7 Each year, 50 teachers are recognized as a State Teacher of the Year. The list that NNSTOY provided for the survey does not include every State Teacher of the Year from the mid-1970s to 2013 because some of the older members do not have e-mail addresses and/or those e-mail addresses were not available to NNSTOY.

8 As mentioned previously, this section was renamed Novice Stage.
} 
The database was reviewed for possible invalid values, skip-pattern violations, and other data anomalies, but missing data were not imputed. Because this is a universe study, no weights were created.

\section{Respondent Characteristics}

Table A2 shows the characteristics of the 311 respondents based on data collected in the background section of the survey. On average, the respondents to this study are older and have more teaching experience than $\mathrm{K}-12$ teachers nationwide. Almost 60 percent of the respondents are older than 50 years old, while the average age of $\mathrm{K}-12$ teachers in the United States is about 41 (Goldring, Gray, \& Bitterman, 2013); 58 percent of these teachers have more than 20 years of teaching experience, while the average years of teaching in United States is about 14 years (Goldring et al., 2013); and approximately 15 percent of the respondents have retired. Half of the survey respondents currently are teaching in a PK-12 classroom (41 percent as a regular teacher and 9 percent in a specialist role). The rest currently serve in such roles as a school specialist or a school or district administrator (10 percent), teach at the college level (4 percent), or perform some other activities (15 percent). Many of the respondents had taught more than one grade level over the years, with the majority of the teachers (61 percent) having taught in high schools. Similarly, the respondents had held multiple teaching assignments during their careers; some of the most common ones were elementary general education (34 percent), English (34 percent), reading and language arts (28 percent), social studies (24 percent), and science (23 percent). Many teachers also had taught in more than one type of school location and more than one type of school in terms of the proportion of students who were eligible for free or reduced-price lunch.

For more information about State Teachers of the Year, please see http://www.nnstoy. org/; for more information about National Teachers of the Year, please see http://www. ccsso.org/ntoy.html. 
Table A2. Characteristics of Survey Respondents

\begin{tabular}{|c|c|c|}
\hline 1. Are you currently teaching in a PK-12 classroom? & $n$ & $\%$ \\
\hline a. Yes, as a classroom teacher. & 126 & $41 \%$ \\
\hline b. Yes, in a specialist role. & 28 & $9 \%$ \\
\hline c. No, I am currently in school or district administration. & 32 & $10 \%$ \\
\hline d. No, I am currently in an in-building teacher leadership role. & 7 & $2 \%$ \\
\hline e. No, I am currently teaching at the college level. & 13 & $4 \%$ \\
\hline f. No, I am currently at a nonprofit education organization. & 10 & $3 \%$ \\
\hline g. No, I am currently at a for-profit education organization. & 1 & $0.3 \%$ \\
\hline h. No, I left the field of education. & 0 & $0 \%$ \\
\hline i. No, I am currently retired but am still involved in education through community work. & 30 & $10 \%$ \\
\hline j. No, I am currently retired and am not currently involved in education. & 17 & $5 \%$ \\
\hline k. Other (specify): & 47 & $15 \%$ \\
\hline $\begin{array}{l}\text { 2. Excluding student teaching, what is your total number of years of teaching } \\
\text { experience overall in a PK-12 setting? }\end{array}$ & $n$ & $\%$ \\
\hline a. Less than 5 years & 0 & $0 \%$ \\
\hline b. $5-10$ years & 24 & $8 \%$ \\
\hline c. $11-15$ years & 54 & $17 \%$ \\
\hline d. $16-20$ years & 52 & $17 \%$ \\
\hline e. More than 20 years & 180 & $58 \%$ \\
\hline 3. How old are you? & $n$ & $\%$ \\
\hline a. Under 25 & 0 & $0 \%$ \\
\hline b. $25-30$ & 4 & $1 \%$ \\
\hline c. $31-35$ & 20 & $6 \%$ \\
\hline d. $36-40$ & 33 & $11 \%$ \\
\hline e. $41-45$ & 37 & $12 \%$ \\
\hline f. $46-50$ & 37 & $12 \%$ \\
\hline
\end{tabular}




\begin{tabular}{lll}
\hline g. $51-55$ & 47 & $15 \%$ \\
\hline h. $56-60$ & 43 & $14 \%$ \\
\hline i. Over 60 & 90 & $29 \%$
\end{tabular}

4. What grade level(s) have you taught during your teaching career, excluding student teaching?

$\%$

\begin{tabular}{lrc} 
a. PreK & 20 & $6 \%$ \\
\hline b. K-3rd Grade & 116 & $37 \%$ \\
\hline c. 4 th-6th Grade & 135 & $43 \%$ \\
\hline d. 7 th-8th Grade & 146 & $47 \%$ \\
\hline e. 9 th-12th Grade & 189 & $61 \%$
\end{tabular}

5. What teaching assignment(s) have you held during your career, excluding student teaching?

$\%$

a. Elementary general education

$106 \quad 34 \%$

\begin{tabular}{lcc}
\hline b. Math & 65 & $21 \%$ \\
\hline c. Science & 73 & $23 \%$ \\
\hline d. English & 105 & $34 \%$ \\
\hline e. Social studies & 76 & $24 \%$ \\
\hline f. World language & 23 & $7 \%$ \\
\hline g. English as a second language & 19 & $6 \%$ \\
\hline h. Special education & 31 & $10 \%$ \\
\hline i. Reading/language arts & 87 & $28 \%$ \\
\hline j. Early education & 16 & $5 \%$ \\
\hline k. Physical education & 21 & $7 \%$ \\
\hline I. Fine arts (music, drama, art) & 35 & $11 \%$ \\
\hline m. Family and consumer science & 7 & $2 \%$ \\
\hline n. Library media specialist & 7 & $2 \%$ \\
\hline o. School guidance counselor & 3 & $1 \%$ \\
\hline p. Career education & 15 & $5 \%$ \\
\hline
\end{tabular}




\begin{tabular}{lrr}
\hline q. Technology literacy & 28 & $9 \%$ \\
\hline r. Other (specify): & 53 & $17 \%$
\end{tabular}

\section{What type(s) of school(s) have you taught in during your teaching career,} excluding student teaching?

a. Traditional public school

$307 \quad 99 \%$

$\begin{array}{lll}\text { b. Charter school } & 13 & 4 \%\end{array}$

\begin{tabular}{lll} 
c. Private school & 35 & $11 \%$ \\
\hline
\end{tabular}

$\begin{array}{lll}\text { d. Alternative public school } & 15 & 5 \%\end{array}$

$\begin{array}{lll}\text { e. Department of Defense Education Activity School } & 4 & 1 \%\end{array}$

$\begin{array}{lll}\text { f. Other (specify): } & 26 & 8 \%\end{array}$

7. In which type of school location(s) have you taught during your teaching career, excluding student teaching?

a. Urban school

$128 \quad 41 \%$

$\begin{array}{lll}\text { b. Suburban school } & 170 & 55 \%\end{array}$

$\begin{array}{lll}\text { c. Rural school } & 132 & 42 \%\end{array}$

$\begin{array}{lll}\text { d. School in a foreign country } & 20 & 6 \%\end{array}$

8. What percentage of students in the school(s) where you have taught during
your teaching career were approved for free or reduced-price lunch?

$\begin{array}{lll}\text { a. } 0-25 \text { percent } & 109 \quad 34 \%\end{array}$

$\begin{array}{lll}\text { b. } 26-50 \text { percent } & 124 & 40 \%\end{array}$

$\begin{array}{lll}\text { c. } 51-75 \text { percent } & 91 & 29 \%\end{array}$

\begin{tabular}{lll} 
d. $76-100$ percent & 76 & $24 \%$ \\
\hline
\end{tabular}

$\begin{array}{lll}\text { e. Don't know } & 9 & 3 \%\end{array}$

Source: Survey Results: Teacher Perspectives on Factors Influencing Effectiveness (Center on Great Teachers and Leaders \& National Network of State Teachers of the Year, 2014)

Note: Data come from the 311 teachers who completed the survey. Numbers and percentages in items 4-8 add up to more than 311 and 100 percent because these items allowed respondents to select more than one response. 



\section{SePNNSTOY}

National Network of State Teachers of the Year

1201 Connecticut Avenue NW, Suite 300

Washington, DC 20036

609.992.5532

www.nnstoy.org

\section{Center on}

\section{GREAT TEACHERS \& LEADERS}

at American Institutes for Research

1000 Thomas Jefferson Street NW

Washington, DC 20007-3835

877.322.8700

www.gtlcenter.org

\section{큐IR \\ AMERICAN INSTITUTES FOR RESEARCH}

\section{www.air.org}

Copyright (C) 2014 American Institutes for Research. All rights reserved.

This work was originally produced in whole or in part by the Center on Great Teachers and Leaders with funds from the U.S. Department of Education under cooperative agreement number S283B120021. The content does not necessarily reflect the position or policy of the Department of Education, nor does mention or visual representation of trade names, commercial products, or organizations imply endorsement by the federal government.

The Center on Great Teachers and Leaders is administered by American Institutes for Research and its partners: the Council of Chief State School Officers and Public Impact. 